\title{
A virada e a imagem: história teórica do pictorial/iconic/visual turn e suas implicações para as humanidades
}

The turn and the image: a theoretical history of the pictoria-iconic-visual turn and its implications in the human sciences

http://dx.doi.org/10.1590/1982-02672019v27e08

\section{FRANCISCO DAS CHAGAS FERNANDES SANTIAGO JÚNIOR'}

https://orcid.org/0000-0003-2690-5222

Universidade Federal do Rio Grande do Norte / Natal, RN, Brasil

RESUMO: Este texto historiciza a composição da virada visual e sua importância para as humanidades na contemporaneidade. No Brasil, o debate foi introduzido por Ulpiano Meneses, em artigo hoje antológico, com perspectivas ampliadas posteriormente por Paulo Knauss. A proposta deste artigo é evidenciar o duplo batismo da "virada à imagem": nos Estados Unidos, em 1992, como pictorial turn por William John Thomas Mitchell no surgimento dos visual studies (estudos visuais); e na Alemanha, em 1994, como iconic turn por Gottfried Boehm, nas bases da atual Bildwissenschaft (ciência da imagem), questão pouco debatida no Brasil. Apresentam-se os desdobramentos do uso da expressão, a transformação da pictorial turn em visual turn na passagem dos anos 1990 para os 2000, e as aproximações entre a vertente norte-americana e a alemã a partir dos anos 2000, o que causaria um retorno às propostas originais. Ao fim do texto condensamos suas propostas para as humanidades e para os estudos da cultura material. A virada pictórica/icônica/ visual é tomada como uma metáfora absoluta, um campo de problematização cuja compreensão deve ser ativada por sua historicização como debate acadêmico e diagnóstico sobre questões do mundo passado e contemporâneo.

PALAVRAS-CHAVES: Virada visual. Cultura visual. W. J. T. Mitchell. Gottfried Boehm.

1. Professor no Departamento de História e no Programa de PósGraduação em História da Universidade Federal do Rio Grande do Norte (UFRN). Mestre em Multimeios pela Universidade Estadual de Campinas (Unicamp) e doutor em História pela Universidade Federal Fluminense (UFF). E-mail: <santiago.jr@gmail.com> 
ABSTRACT: this text historicizes the composition of the visual turn and its importance to the humanities in the contemporaneity. In Brazil, the debate was introduced by Ulpiano Meneses in an anthological article, with perspectives later amplified by Paulo Knauss. The proposal of this article is: to highlight the double baptism of the turning to the image: in the USA, in 1992, as pictorial turn by William John Thomas Mitchell in the emergence of visual studies; and in Germany, in 1994, as iconic turn by Gottfried Boehm on the basis of the current Bildwissenschaft (Science of Image), an issue poorly debated in Brazil. Then, unfoldings of the use of the expression are presented, the transformation of the pictorial turn into a visual turn in the passage from the 1990s to the 2000s, and the approximations between the North American and the German aspects from mid 2000s, which would cause a return to the original proposals. At the end of the text we synthesize his proposals for the humanities and the studies of material culture. The pictorial/iconic/visual turn is taken as an absolute metaphor, a field of problematization, whose understanding must be activated by its historicization as academic debate and diagnosis on issues of the past and contemporary world.

KEYWORDS: Visual turn. Visual culture. W. J. T. Mitchell. Gottfried Boehm. 
Entre as muitas facetas do avanço do conservadorismo político brasileiro no pós-2016, destacam-se as formas misóginas de agressão, as quais parecem ter encontrado um paradigma na abertura do seminário "Os fins da democracia", no Sesc Pompeia, São Paulo, em novembro de 2017: em meio a bandeiras do Brasil e pessoas empunhando cruzes com gritos xenófobos, uma boneca de bruxa com a foto de Judith Butler, filósofa norte-americana, foi queimada na frente do Sesc, no exato dia da conferência ministrada pela intelectual, que também era uma das organizadoras do evento. $\bigcirc$ episódio mostrava a sobreposição de uma atual figura feminina de destaque à ameaçadora imagem de bruxa, em um ato que retomou perseguições misóginas do passado e atualizou a caça às bruxas no século XXI a partir de uma ação iconoclasta. A boneca reificava a filósofa por meio de sua foto e estava ali para construir uma alteridade: ela (boneca-Butler) era a outra (mulherfeminista-queer-bruxa-estrangeira), como ficou registrado pelas câmeras dos celulares dos presentes. Montou-se uma inesperada emboscada para o olhar ${ }^{2}$ misógino que ali protestava: a boneca-alteridade-mulher era uma imagem, uma alteridade reconhecida por seus usuários. Reconhecer a imagem como "alteridade" é o deslocamento fundamental da chamada "virada visual".

Saber e agir a imagem como "algo". Talvez ela seja forma de vida, protopessoa, ou somente artefato vazio, mas sempre outra, dotada de um grau variado de diferença icônica. As atitudes perante objetos da vida material aos quais atribuímos nomes de imagens são atos de construção de sua alteridade, que podem ser encontrados em inúmeras situações: queimar uma boneca-bruxa com efígie da filósofa feminista Judith Butler; ${ }^{3}$ colar no carro um adesivo da ex-presidente Dilma Rousseff com vulva exposta, para toda vez repetir um estupro simbólico quando se abastece o combustível; 4 replicar viralmente a foto do ex-presidente Lula, tirada por Francisco Proner, no ato de sua prisão em 2018; ${ }^{5}$ destruir uma cidademonumento como Palmira, realizado pelo Estado Islâmico (Isis); 6 encenar um videoclipe de afirmação racial no Museu do Louvre, contrapondo-se à história da arte branca, como fizeram Beyoncé e Jay-Z; ${ }_{i}^{7}$ tentar retirar a imagem de lemanjá do rio São Francisco, em Juazeiro (BA). ${ }^{8}$ A virada visual ocorre quando emerge a consciência da perturbação e ansiedade que as imagens criam ou canalizam no espaço público.

Cumpre, portanto, entender o que é o reconhecimento da alteridade da imagem como "paradigma/tropo" da "virada visual" à qual os comunicólogos, historiadores, museólogos, antropólogos e outros se referem nos últimos anos, a partir dos estudos de história e imagem. Este texto almeja esclarecer um tópico da discussão ainda inexplorado na bibliografia brasileira ou em língua portuguesa. Explicitaremos as origens do conceito de "virada visual" em suas primeiras
2. Segundo Hans Belting (2008), o olhar é invisível, uma vez que o sujeito olha de dentro dele, de maneira que só se pode observar seus efeitos por meio de uma armadilha ou emboscada.

3. Cf. Gonçalves (2017).

4. Cf. Governo faz denúncia... (2015).

5. Cf. A prisão de... (2018).

6. Cf. Presse (2015).

7. Apes**t... (2018).

8. Cf. Pedido de retirada... (2015). 
9. Anos depois o próprio Meneses (2005, 2012) retomaria e desenvolveria os temas.

10. Knauss (2006; 2008).

11. Mitchell (1994).

12. Id., 2006, p. 105 manifestações - como pictorial turn, segundo William John Thomas Mitchell, em 1992, na base dos visual studies; e como iconic turn, conforme Gotfried Boehm, em 1994, na base da Bildwissenschaft (ciência da imagem) - bem como a sua conversão em visual turn nos anos seguintes. As perguntas-base são: como surgiu a heurística da imagem como "virada/transformação" na perspectiva das humanidades? Por quais transformações tal perspectiva tem passado? Trata-se de "moda" ou novo encaminhamento?

Já se foram quase quinze anos desde que Ulpiano Bezerra de Meneses publicou o texto Fontes visuais, cultura visual, história visual, apresentando aos historiadores brasileiros e estudiosos da imagem e da cultura material uma apreciação de uma série de perspectivas, muitas delas já em curso no país, mas que até então não haviam encontrado sistematização. Meneses apresentou problemas, interesses e vasta bibliografia internacional. ${ }^{9}$ Anos depois, Paulo Knauss publicaria textos fundamentais, destacando-se $\bigcirc$ desafio de fazer história com imagens e Aproximações disciplinares: arte, história e imagem. O primeiro aborda a questão da história visual como plataforma de problematização dos processos históricos, por meio da reflexão sobre a visualidade e a cultura visual; o segundo se debruça sobre as tradições dos visual studies e a Bildwissenschaft. Talvez até hoje sejam as sínteses centrais na bibliografia brasileira, e não apenas para historiadores. ${ }^{10}$ Ambos citam de forma periférica a questão da "virada visual". Segundo Knauss, esta noção fora cunhada diretamente por Mitchell, no primeiro capítulo da Picture theory, ${ }^{11}$ e teve sua importância ampliada por Martin Jay:

A categoria de virada se torna um ponto de discussão das propostas de demarcação da abordagem do conceito de cultura visual. A particularidade do trabalho de Martin Jay vai se traduzir em texto mais recente, no qual substitui a categoria de pictorial turn pela de visual turn ou virada visual. Abandona a ênfase no pictórico, ou figurado, para acentuar o visual e a visualização. A nuance da diferença, traduzida no jogo de palavras, fica mais clara em inglês do que na sua tradução. ${ }^{12}$

Também Ulpiano Meneses, com alguma ironia, já havia alinhado o problema:

A voga dos estudos de "cultura visual" assinala com clareza, no campo das ciências sociais - para o bem e para o mal -, aquilo que já foi chamado de pictorial turn, em seqüência ao linguistic turn de décadas anteriores, que chamara a atenção para o texto antropológico ou sociológico na produção do conhecimento. (Até a História, diga-se de 
passagem, principalmente a História Cultural, ainda que tardiamente e sem maiores cuidados, deixou-se tocar por esta primeira reformulação de paradigmas, mas ainda não tomou ciência da segunda). A metáfora da "leitura de textos", que ilustrava (mais que expressava) o antigo paradigma, agora cede lugar, na expressão de Martin Jay, a "models of spectatorship and visuality". ${ }^{13}$

problema da "virada", no geral, foi destacado como já dado, passando pela noção de uma primeira virada pictórica, idealizada por Mitchell, para sua eventual lapidação como "virada visual" por Martin Jay. ${ }^{14}$ Apesar de muito mencionada, a "virada visual" raramente foi explicada em sua formulação como proposta de trabalho com imagens, aparecendo mais como traço de contextualização bibliográfica. ${ }^{15}$ No Brasil nem sequer é comum recordar que, paralela à essa ideia, surgira na Alemanha a iconic turn (virada icônica) idealizada por Gottfried Boehm e outros historiadores/estudiosos das imagens.

Este texto visa reconstruir os termos do debate sobre a(s) virada(s) pictórica/ icônica, obviamente elaborada(s) junto da noção de cultura visual e de história das imagens na base original dos visual studies e da Bildwissenschaft. ${ }^{16}$ Nossa opção foi por acompanhar a "virada pictórica/icônica" como um paradigma/tropo pelos seus primeiros propositores (Boehm e Mitchell), a partir da sua história como metáfora absoluta, seguindo a abordagem de Hans Blumemberg. ${ }^{17}$

$\bigcirc$ termo "virada" 18 descende da antiga metáfora absoluta da revolução copernicana. ${ }^{19}$ A metáfora absoluta é um modelo do qual se obtém uma regra de reflexão que se aplica no uso de outras ideias - uma espécie de símbolo. Trata-se da "forma da reflexão" que permite organizar conceitos e imagens. Os movimentos, concepções e articulação da metáfora absoluta da virada podem ser seguidos por meio de sua história. Busca-se, portanto, a história da inversão produzida pela concepção de alteridade das imagens como um campo regulador da compreensão das experiências sociais.

Primeiro situamos o debate em seu quadro internacional, evidenciando as diferentes tradições nas quais emergiram a reflexão sobre imagem e virada, na Alemanha e nos Estados Unidos (EUA), a partir das obras de Boehm e Mitchell, os dois autores alicerces da reflexão mais sistemática sobre imagens e cultura visual no mundo contemporâneo. Em seguida, reconstruímos a transformação do tópico das viradas pictórica/icônica em visual nos anos 2000. Por fim, apresentamos os momentos mais recentes deste debate internacional ${ }^{20}$ e evidenciamos como a virada à imagem, no Brasil, tem sido reconduzida ao redor de princípios de vida, corpos e usos da iconicidade na cultura material.
13. Meneses (2004, p. 23).

14. Jay (2003-2004).

15. Nos anos 2010 ampliaram-se publicações e tentativas de construir orientações, como se pode ver em Costa e Schiavinatto (2016); Flores (2011, 2013); Meneses (2012); Monteiro (2013); além dos importantes dossiês em periódicos como ArtCultura (Flores, 2010; Lehmkuhl, 2006); Boletim do Museu Goeldi (Mauad; Lopes, 2014); História (Kern; Kaminski, 2014); PerCursos (Souza, 2016); e Estudos Ibero-Americanos (Mauad; Monteiro, 2018). Os exemplos poderiam ser multiplicados na produção nacional incluindo, além de revistas como Domínios da imagem, coletâneas organizadas por inúmeros pesquisadores.

16. Paulo Knauss (2008) sistematizou as duas vertentes (visual studies anglo-americanos e Bildwissenschaft alemã), situando o debate internacional nos EUA e na Alemanha. Especialmente importante é sua sistematização da noção de cultura visual (p. 157-161) e sobre a história das imagens (p. 163-165). Andrea Pinotti e Antonio Somaini (2016, p. 3-66) fizeram uma reconstrução ampliada do tema.

17. Blumemberg (2018).

18. Turn, em inglês; wendung, em alemão; svolta, em italiano; também giro, em português.

19. Segundo Blumenberg (2018), Kant foi o primeiro a dar explícita formulação à revolução copernicana, depois retomada de modos diversos por vários autores, sempre com uma base comum: referir-se a "uma inversão figura-fundo, exceção-regra, particular- 
geral, para a qual velhos sistemas não têm uma palavra" (Melandri, 2018, p. 161) ou conceito capaz de reunir todos os elementos técnicos e situações específicas a serem descritas. Boehm (2009a, 2012) retoma a reflexão de Blumenberg para justificar sua iconic turn.

20. Deve-se levar em conta a condição pós-colonial de produção deste texto, compreendendo que, se a discussão sobre visual turn tem origem estrangeira (e aqui surge mediada pelo diálogo com uma semiperiferia italiana da indústria acadêmica n e o c a p i a 1 is t a contemporânea), as preocupações com imagens no Brasil são nativas $\mathrm{e}$ possuem histórico. Compreendemos que a condição do texto o lança em uma história atlântica da virada à imagem.

21. As duas mais amplas referências bibliográficas da emergência desse debate no contexto europeu e americano são Downcast eyes (Jay, 1993) e Cultura visuale (Pinotti; Somaini, 2016). Existem coletâneas importantes que apresentam os quadros de emergência e os debates de época, mas o texto de Jay permanece referência ampla da constituição do problema da imagem e do olhar no Ocidente; o texto de Pinotti e Somaini sistematiza e apresenta os campos de debate sobre cultura visual, olhar e dispositivo produzidos em língua alemã, francesa, inglesa e italiana. Recomenda-se ainda a leitura de Idea (Panosfky, 2013), Arte $e$ ilusão (Gombrich, 2007) e The science of art (Kemp, 1990).

22. Embora tenha começado a ficar famoso após a publicação do livro de Svetlana Alpers, $A$ arte de

\section{BOEHM: DA CARNE DA IMAGEM À VOLTA ICÔNICA}

A reflexão sobre a imagem não é nova. Não seria possível definir neste texto quando ela começou. ${ }^{21}$ Já a reflexão sobre a "cultura visual" é mais recente, remontando à primeira teoria do cinema, de Béla Balázs, em 1924, ${ }^{22}$ enquanto a da "virada visual" é recentíssima, com pouco mais de 25 anos. A maioria dos compêndios que organizam a apresentação das matrizes da cultura visual considera a emergência da civilização industrial como momento decisivo de uma nova consciência social e intelectual sobre as imagens. ${ }^{23}$ À parte as polêmicas sobre a adequação da noção de cultura visual às épocas pré-fotográficas, ${ }^{24}$ sua importância advém do debate no início dos anos 1990 que usou da metáfora absoluta da "virada" - adjetivada "pictórica/icônica" - como chave interpretativa do deslocamento epistemológico produzido pelas noções de imagem e olhar em diferentes campos das humanidades.

Sob a "virada", a reflexão sobre a imagem deu emergência às "novas" tradições da new iconology (nova iconologia) norte-americana e da Bildwissenschaft ("ciência da imagem") alemã. Nesta última o nome catalisador fora o de Gotffried Boehm, ${ }^{25}$ o qual cruzaria a hermenêutica alemã, a fenomenologia alemã-francesa, a "ciência sem nome" 26 de Aby Warburg e a pura visualidade austríaca. Boehm faz parte de um conjunto de estudiosos da história da arte que se debruçaram sobre a passagem do período medievo para o Renascimento e que se tornaram fulcrais para a formulação de novas propostas de trabalho. ${ }^{27}$ As reflexões de Boehm dialogavam e constituíam o que mais tarde foi chamado de Bildwissenschaft. Segundo Bredekamp, ${ }^{28}$ estas novas propostas - cujos antecedentes mais extraordinários foram a ciência da cultura de Jacob Burkhardt e Aby Warburg, ${ }^{29}$ e o puro visualismo - sugeriam nos anos 1970 novas direções a partir história da arte. ${ }^{30}$

Retornando a Boehm, formado em história da arte, filosofia e germanística pelas Universidades de Köln, Wien e Heidelberg entre 1961 e 1968, o autor desenvolveu sua perspectiva única entre 1972 e 1974, quando trabalhou com o retrato renascentista do período 1470-1520 e elaborou texto somente publicado em 1985. ${ }^{31}$ Ali sua tese central era que, se a retratística apresentava visualmente pessoas reais na pintura do Renascimento, ocorreu uma mudança na qual a soberania do retratado e sua individualidade puderam emergir a partir de uma lógica visual nova, que se recusava a depender de fórmulas textualizadas - o autor recusava uma iconologia e iconografia repressoras das imagens por meio das fórmulas textuais do tipo de Erwin Panofsky. Emergia a imagem do retratado como diferença que só poderia gerar identidade justamente porque havia algo que só o retrato, como coisa visual, fazia ver. 
A trajetória inusitada de Boehm evidencia a peculiaridade de sua preocupação filosófica. Sua monografia fora orientada por Hans-Georg Gadamer, mais conhecido como um dos expoentes da virada linguística na hermenêutica filosófica, cumprindo um papel insuspeito na orientação de estudos sobre imagens que buscavam capturar sua especificidade. ${ }^{32}$ Boehm estudava a obra do primeiro teórico da arte figurativa contemporânea, Konrad Fiedler, estava relacionado a um cenário filosófico amplo na Alemanha e pesquisava a transição da "era das imagens" para a "era das artes". Desde os anos 1970 escrevia sobre a hermenêutica da imagem como um "método" diferenciado que apontava para a combinação com uma atitude dêitica ${ }^{33}$ em relação às imagens. ${ }^{34}$

Na segunda metade do século XX, a história da arte alemã - remetendo a Aby Warburg e à Escola de Viena - abraçou a definição de bild (imagem ${ }^{35}$ ) com toda sua amplitude linguística e deu espaço à elaboração de uma série de abordagens históricas que trataram de vários suportes e gêneros visuais sem hierarquia. Ao contrário da geração de Erwin Panosfky e Ernest Gombrich, menos interessada na arte moderna, ${ }^{36}$ as gerações de Boehm e companhia se sentiram estimuladas pelo "culto da heresia" dos modernistas ${ }^{37}$ em suas dimensões formais, filosóficas e históricas. Para eles, compreender a arte moderna era fundamental para refazer o caminho da história da arte e compreender a arte na história. Bredekamp ${ }^{38}$ destaca que a formulação de uma nova abordagem sobre a imagem na Alemanha se devia tanto a uma popularização de novas tecnologias /como a fotografia) no trabalho de historiadores da arte, quanto à reconsideração sobre o papel da arte moderna e contemporânea na reflexão de historiadores da arte.

No meio alemão os trabalhos já citados de Konrad Fiedler, na segunda metade do século XIX, foram importantes para articular uma nova abordagem da bild. Fiedler ${ }^{39}$ postulou para a imagem uma validade gnoseológica irredutível ao modelo de linguagem. $\bigcirc$ autor tinha pretensão de "purificar o ver de toda interferência do saber, do ouvir e do recordar". 40 Segundo Gottfried Boehm, Fiedler tentou resolver a dúvida kantiana da "coisa em si", reconhecendo a atividade do olho como o paradigma central da filosofia, e transformou o ato de ver em um processo explicativo - não mais receptivo - no qual o fluxo de dados se articula na consciência e o mundo emerge como visibilidade, de maneira que "ver é o princípio sobre o qual se funda tanto a realidade como a consciência, é um ato puramente criativo". ${ }^{41} \bigcirc$ mérito de Fiedler foi ter transformado a sensibilidade de ato passivo em ato ativo na economia do intelecto do século XIX, conferindo ao olho uma determinância desconhecida até então. ${ }^{42}$ Fiedler também fora central para o desenvolvimento das pesquisas de Max Imdahl, 43 interlocutor de Boehm. descrever, de 1983 (1999), o termo cultura visual foi usado pela primeira vez em 1924 por Béla Balázs (visualle Kultur, no seu primeiro volume de teoria do cinema L'uomo visibile) e por László Moholy-Nagy - e não por Towards a visual culture, de 1969, escrito por Caleb Gattegno, como advoga Margaret Dikovitskaya (2005). Cf. Balázs (1954); Costa; Schiavinatto (2016); Pinotti; Somaini (2016)

23. Cf. Costa; Schiavinatto (2016); Jay (1996b); Mirzoeff (1997, 1998, 2018); Bryson; Holly; Moxey (1991); Moxey (2008); Pinotti, Somaini (2009, 2016); Meneses (2004); Knauss (2006); Alloa (2012).

24. Cf. Farago (2016); Jenks (1995); Knauss (2006); Mirzoeff (1999).

25. O único texto de Boehm traduzido encontra-se na coletânea Pensar a imagem (2015). Os estudos de Boehm remetem diretamente à elaboração da heurística dos trabalhos com imagens, entre os quais se destacam atualmente a teoria dos atos icônicos de Horst Bredekamp (2015) e a antropologia da imagem de Hans Belting (2001) e Carlo Severi (2018), muito afinadas com a teoria da agência de Alfred Gell (1998). A potencialidade historiográfica deste último já fora assinalada por muitos comentadores recentes, entre eles Mauad (2014) e Meneses (2012).

26. Agamben (2015).

27. Luca Vargiu (2012) já chamou atenção ao fato de vários estudos sobre esse período terem definido rumos das pesquisas visuais e deslocamentos heurísticos e epistemológicos que ressoam não apenas na obra de Boehm, como na do próprio Mitchell. 
28. Bredekamp (2003).

29. Sobre Warburg e a história da arte e sua relação com Burkhardt, cf. Fernandes (2006) e Lissovsky (2014).

30. Citando apenas alguns autores de destaque: Max Imdahl (2012), historiador da arte interessado em romper com a história da arte convencional alemã, num método voltado a um ver recognoscitivo que fosse interessado pelos traços propriamente visuais das obras, como no estudo Giotto: zur Frage der ikonischen Sinnstruktur (Giotto: sobre a questão da estrutura icônica do significado), de 1979. O próprio Boehm indagava, no início da carreira, a teoria da percepção renascentista e m Studiennzur Perspektivität: philosophie und Kunst in der früben Neuzeit (Estudos sobre perspectivas: filosofia e arte nos primeiros tempos modernos), de 1969, e Bildnis und Individuum. Über den Ursprung der Portraitmalerei in der italienischen Renaissance (Retrato e indivíduo: sobre a origem do retrato no Renascimento italiano), de 1985; Hans Belting pesquisava a história da arte a partir dos artefatos, arte e público em Bild und Publikum im Mittelalter (A arte e seu público: função e forma das imagens antigas da paixão), de 1981, iniciando uma trajetória que culminaria na proposta de uma história das imagens antes da arte em Bild und Kult. Eine Geschichte des Bildes vor dem Zeitalter der Kunst (Imagem e culto: uma história das imagens antes da arte), de 1990; Horst Bredekamp começou indagando a iconoclastia em Kunst als Medium sozialer Konflikte. Bilderkämpfe von der Spätantike bis zur Hussitenrevolution (Arte como meio de conflitos
A rigor, em Fiedler havia uma concepção de produção de realidade pelo ato de ver, que se estende corporalmente do olho à atividade manual. Boehm realizava leituras sobre Fiedler desde os anos 1960, chegando a editar, em 1971, o volume Schriften zur Kunst, reunião dos escritos do autor. As concepções de Fiedler foram, portanto, uma de suas portas de entrada, junto da tradição warburguiana, na ideia de imagem como produção e não apenas reprodução da realidade. A teoria de Fiedler, a heurística visual da migração de imagens como cognoscibilidade do Atlas mnemosine de Warburg, ${ }^{44}$ a hermenêutica das imagens via Gadamer e a fenomenologia de Edmund Husserl e Maurice MerleauPonty ocupam lugares estratégicos nas referências de Boehm, que, entre outros métodos de trabalho, transformou em premissa a imagem como pedra de toque de revisão da história da filosofia.

Boehm, a partir das indicações de Gadamer e explorando sua principal obra, Verdade e método, desenvolveu pela primeira vez a concepção de "icônico" como uma diferenciação na percepção/consciência. Foi seguindo a peculiaridade da teoria da representação visual em Gadamer, a qual Boehm explorou em sucessivos textos, ${ }^{45}$ que o historiador e teórico da imagem desenvolveu sua questão fundamental - o que é uma imagem? - conduzindo a uma resposta já esboçada em sua tese sobre a individualidade do retrato renascentista. Destaque-se um importante seminário sobre estética e hermenêutica, de 1978, em homenagem a Gadamer, no qual Boehm apresentou o estudo Por uma hermenêutica da imagem (Zu einer Hermeneutik des Bildes), ${ }^{46}$ no qual se perguntava sobre a relação entre linguagem e imagem. Naquele texto citava Fiedler e iniciava a reflexão sobre a diferenciação da linguagem, que estará na base do que ele chamará anos depois de virada icônica. Segundo Boehm, ainda que a tentativa de falar de uma hermenêutica da imagem não tenha muitos precursores, nunca chegou a supor que a "compreensão" fosse apenas um processo linguístico. Foi a arte moderna que colocou em primeiro plano o problema da diferença entre imagem e palavra, pela renúncia da semântica e da denotação reprodutiva. Para Boehm, apenas com o advento das variantes de arte moderna emergiu uma tarefa que pode ser computada como uma hermenêutica da imagem. Esse advento teve efeito reflexivo sobre a própria história das artes e imagens precedentes, as quais ressurgem como dotadas de alteridade em relação à linguagem. A tematização dos elementos figurativos era um sinal de que o "próprio" da imagem se tornara um problema da prática e da teoria artísticas, bem como da falta de recursos que a linguagem oferecia no tratamento das imagens: 
A identidade de uma coisa pintada, por exemplo, se constitui totalmente diversa. Não se pode arrancar as árvores que aparecem na imagem de um lugar e do contexto em que aparecem. Se isso acontece, isso significaria uma imagem totalmente nova, na qual, contudo, a árvore permaneceria novamente inseparável da condição de sua aparição. Estas observações reenviam a uma característica "ontologia" da imagem, que necessita de posterior esclarecimento. A indistinguibilidade de ser e aparência na imagem pode, contudo, por hora, chamar-se, em sentido literal, sem-nome, sem-linguagem, a-fona e silenciosa. A proposição enunciativa se distancia da aparência da imagem, porque nessa não se pode verificar o seu pressuposto, a separação do sujeito-coisa e predicado mutável. $\bigcirc$ icônico e o linguístico se encontram repudiando-se como estrangeiros. A lógica diferente das imagens requer que se fale de imagens sem deformações. ${ }^{47}$

Naquele texto o autor elaborou, a partir da teoria da representação de Gadamer, um caminho heurístico para pensar o "icônico" (termo que tomou emprestado de Max Imdah|48) e a iconicidade, investigando o que ele chamava, então, de metaforicidade da imagem como distinta da metaforicidade da linguagem. No ano seguinte Boehm, no ensaio Bildsinn und Sinnesorgane, lançava o primeiro alicerce da sua concepção de imagem como diferença da linguagem. autor tornou o conceito famoso como "diferença icônica":

entre a superfície e o elemento que se encontra nela se produz uma relação. $\bigcirc$ olho percebe uma ligação, não um signo, e nem mesmo uma figura. A ligação permite perceber aquilo que se vê enquanto tal, e isso funda uma relação elementar que chamaremos diferença icônica. O que explica porque uma imagem é um medium, um tipo de "linguagem", isto é, um sistema autônomo de significação (não figura, espelho da realidade, não um invólucro espacial de coisas, não uma série de signos, etc.). [...] A separação (a diferença) dos elementos que se encontram sobre a superfície da superfície em si mesma produz uma tensão (a diferença icônica) que reporta o olhar do observador (o seu senso de tempo) à sua essência (isto é, ao "sentido"). Importante reter que é o fato de que o simples elemento da superfície (por exemplo um ponto) descreve uma relação que em todo caso é um pontotempo e um ponto-espaço juntos. ${ }^{49}$

A "diferença icônica"50 tornou-se o centro da investigação de Boehm sobre a história da filosofia, já que ele era interessado nas concepções de imagem em inúmeros filósofos do século XX. Boehm foi atento leitor de Merleau-Ponty, em cujas obras encontrou uma primeira versão de seu objetivo: um pensamento no qual as tensões que Boehm tematizava via tradição da hermenêutica, da Bildwissenschafte a da "pura visibilidade"51 - desembocavam em uma matriz filosófica da "virada icônica".

Em 1986 Boehm desenvolveu inicialmente a relação entre imagem e memória, interessado em encontrar em Aby Warburg o "desenvolvimento de uma consciência icônica, a qual seria a capacidade de colocar em evidência a diferença sociais: imagens e lutas da antiguidade tardia à revolução hussita), de 1975 , passando a uma importante indagação sobre cognição, imagem e materialidade em Antikensebnsucht und Maschinenglauben. Die Gescbicbte der Kunstkammer und die Zukunft der Kunstgeschichte (Nostalgia do antigo e o fascínio da máquina: a história do Kunstkammer e o futuro da história da arte), de 1992 (Bredekamp, 2016).

31. Um pequeno resumo está em Boehm (2014).

32. O muito citado texto de Gadamer (2005), Parola $e$ immagine (Palavra $\mathrm{e}$ imagem) corrobora este argumento.

33. Uma atitude dêitica permite realçar o que de não linguagem há numa imagem/artefato que se oferece à visão de qualquer pessoa. A abordagem valoriza a presença do material no qual emerge a imagem, dotado de uma contiguidade espacial em sua manifestação (Moxey, 2008).

34. Monte; Monte (2009, p 24).

35. Bredekamp (2003) publicou um texto programático sobre o assunto: em defesa da "tradição negligenciada", qual seja "a ciência da imagem" (Bildwissenschaft), denunciou a divisão artificial entre arte e imagem, lembrando que a palavra alemã "bild compreende a imagem (image), a imagem material (picture), a figura (figure) e a ilustração (illustration)". O texto publicado inicialmente em Critical Inquiry foi uma provocação direta ao meio intelectual anglo-saxão dos infantes visual studies.

36. Cf. Recht (2012). 
37. Cf. Gay (2009).

38. Bredekamp (2003).

39. Fiedler (2006).

40. Monte; Monte (2009, p. 16).

41. Boehm (2009b, p. 231).

42. Konrad Fiedler escrevia em 1887 (2006, p. 102): "O que foi dito difusamente sobre as representações que dizem respeito a esfera da visão, conforme ao escopo deste ensaio, vale para todas as outras esferas sensoriais. A existência daquilo que parece estar a nossa frente, em uma dada forma definida, isto é do que é sensivelmente presente, está ligada a processos que acontecem na nossa consciência, que estão bem longe de descrever esta presença sensível de uma forma desenvolvida, segundo sua natureza sensivelmente perceptível e representável, em forma e figura determinadas até certo ponto".

43. Uma análise mais detida deste ponto pode ser encontrava em Pietro Conte (2012).

44. Boehm (2009b).

45. A leitura da teoria da representação visual em Gadamer realizada por Boehm tenta desmistificar o papel da linguagem verbal na filosofia do seu professor. Segundo Boehm, o papel da poesia e do discurso poético em Verdade e método estaria ligado à familiaridade de Gadamer com a poesia, mas não a uma absolutização do modelo hermenêutico à linguagem verbal. Foi numa importante resenha da estética de Gadamer que Boehm abriu pela primeira, em 1979, a noção de icônico, que estaria na base de seu conceito de diferença icônica, defendido como programa de pesquisa em real entre visão comum e visão de imagens". ${ }^{52} \bigcirc$ autor defendera que essa consciência existia desde tempos antigos e estava ligada à própria definição de imagem relacionada à memória e ao tempo, bem como possuía importantes raízes antropológicas - e não apenas variações histórico-culturais - ligadas à capacidade humana de "reter o visto". Vale a pena reler um longo trecho de Boehm:

Seja quando reconhecemos qualquer coisa vendo, seja quando a usamos em um exercício plenamente livre ou ilimitado do ver, não registramos simplesmente o que está presente sobre a superfície da imagem, mas ordenamos acima de tudo os dados adquiridos, suplantando o supérfluo, isto é, esquecemos, damos para a percepção uma estrutura na qual o elemento singular mantém o seu legítimo lugar, e, todavia, valoriza o todo [...]. Em geral conseguimos compreender a sucessão de elementos apresentados em uma imagem somente como um contexto, na medida em que estamos em grau de reter diante de nós recordando-o [ao contexto] em um dado apenas visto, e também a sua impressão direta desapareceu no tempo. A cadeia de sucessões se estabelece somente quando à sequência temporal do olhar - com o qual colhemos, por exemplo, as figuras de um quadro de história na sua ordem compositiva - se opõe uma capacidade que, com efeito, não fixa a impressão entre o que vai desaparecendo (isto seria impossível), mas, todavia se fixa presente na lembrança. [...] Mas ainda não podemos falar em "imagem"; de fato, há somente o tipo mais simples de movimento do olhar e então uma mobilidade de atenção segundo uma sucessão, em outras palavras: a presença simultânea de muitos detalhes. De fato, apreendemos a imagem quando a observamos, não como faríamos em uma pura lembrança. Esta última começa quando a visão direta não é mais possível. $\bigcirc$ trabalho da lembrança do qual aqui se trata se insere entre a junção das sucessões e as simultaneidades. Quando chegamos a isso olhamos o quadro sem atraso temporal, no átimo de presente do ver. Produz-se assim uma condição que é livre de lembrança, o zênite da percepção, em que a imagem surge por um momento como pura presença. Esta compreensão do todo, no qual temos diante a nós somente a totalidade da superfície, não dura muito. Além disso, também surge sacrificada uma parte dessa multiplicidade que foi apresentada na própria sucessão. $\bigcirc$ olhar volta agora a imergir-se rapidamente na sequência. Na polaridade visiva da sucessão e da simultaneidade, a imagem desenrola a sua riqueza intuitiva. É um mundo de transição, no qual o menor detalhe possui o seu horizonte, e, todavia, a totalidade do quadro permanece ligada ao todo dos particulares. Isto é, o que de tal modo se verifica é mais do que um simples processo de disposição ordenada linear, é um processo de articulações, já somente pelo fato que muitos desses elementos estão em grau de funcionarem de modos diversos, podendo variavelmente coligar-se entre si, provocando deslizamentos de sentido..$^{53}$

A citação permite visualizar a herança fenomenológica, a noção de percepção como atividade de formação/produção de imagem e a diferença visiva na medida da qual a imagem é concebida como "precária e coerente" simultaneidade de alinhamento de dados firmados e mantidos pela lembrança. Ela funciona como um todo presente que serve como orientação nas sucessivas mudanças de seus estados de percepção iniciais, sempre em constante 
atualização. Longe de constituir um sistema, a imagem é o todo presençamudança retido de elementos associados numa dada superfície que se captura pela lembrança, cujos elementos internos estão em mutação na percepção esta foi, talvez, outra formulação da diferença icônica. ${ }^{54}$ Pensada a partir da Mnemosyne warburguiana, ${ }^{55}$ a imagem, frise-se, não é uma lembrança, mas esta tem um papel fulcral para manter coeso o processo de sua elaboração, chegando a se confundir com o próprio todo da captura mental-plástica da "totalidade como sucessão". Traduzindo essa elaboração a partir da teoria de Hans Belting, 56 num dado objeto, circunstância, mídia, portanto, encarnou-se a imagem como produção do mundo pela mente humana. ${ }^{57}$ Este processo, que pode ser encontrado na análise de uma obra de arte, mas não somente, está universalmente presente em todas as esferas sociais, funcionando como uma espécie de constante antropológica.

A investigação sobre a potência criativa da imagem na fenomenologia levou Boehm a reter o que the parecia mais importante na proposta de MerleauPonty. Em mais de um trabalho o autor alemão ligou Konrad Fiedler a MerleauPonty ${ }^{58}$ e realçou a importância da interpretação do filósofo francês sobre a obra de Paul Cézanne. A interpretação de Boehm destacava a quebra da frontalidade cartesiana no conceito fenomenológico de imagem de Merleau-Ponty. Para este, mais do que estar de frente com o mundo, o olho atua e se move, tactilmente. $\bigcirc$ filósofo francês estaria interessado no meio do mundo, no espaço onde o olho e o mundo se encontram como investimento sensorial, que se gera como a própria presença daquilo que se pode traduzir, do francês, por carne do mundo. A reflexão fenomenológica sobre o olhar de um corpo que se sabe vidente e visível e um olhar olhante que se sabe olhado tornou-se decisiva para Boehm perceber o ver e a imagem, no século XX, como um tipo de organon da filosofia.

Merleau-Ponty desenvolveu a ideia - importante, para Boehm - do logos mudo, o conjunto de produção de mundo que não depende da linguagem. $\bigcirc$ filósofo, embora usasse um modelo de Saussure para elaborar a noção de logos, postulava tal logos como não linguístico. $\bigcirc$ contato com as coisas, segundo Merleau-Ponty, é feito de forma muda e sensorial, numa espécie de discurso silencioso, numa atenção àquilo que o mundo "diz" ao sujeito em seu silêncio. A forma privilegiada pela qual o logos mudo do mundo se exprime seria, "na esfera da experiência do olho e através de seu privilegiado instrumento de representação, a imagem". 59 Boehm retém essa importante noção, que ocupará um papel estratégico em suas reflexões na medida em que o fundamento filosófico do ver tornava-se o centro da própria filosofia.
1994, na coletânea Was ist ein bild? que introduziu a iconic turn e no qual Gadamer consta como um dos precursores do debate sobre imagem. Boehm novamente retornaria à Gadamer com o texto Crescita nell'essere, em 2001 (Boehm, 2009c), além de outras ocasiões.

46. Id., 1986.

47. Ibid., p. 195-196, tradução minha.

48. Imdahl (2012, p. 17) definia o icônico da imagem "como o conteúdo que é dado pela intuição visiva como reflexão sobre o caráter intuitivo da imagem daquilo que somente com a imagem é possível", o qual, como chave, permite compreender fenômenos cuja densidade informacional advém do impulso ou da intuição dos agentes produtores de imagens em produzi-las porque elas possuem qualidades cognoscitivas que somente se vinculam pelo icônico. Trata-se de uma modalidade intuitiva icônica. Esta definição é reapresentada no texto de Imdahl publicado na coletânea Was ist ein bild?, de 1994, organizada por Boehm e na qual este propôs a iconic turn.

49. Boehm (1981, p. 124125 , tradução minha).

50. Claramente baseada na diferença ontológica de Martin Heidegger, que enfrentava a metafísica pela diferenciação capaz de romper a normalidade/ cotidianidade na qual o ser mergulharia no mundo. A diferença ontológica compreende as condições de possibilidade de organização e limites para outros modos de pensar, em que o não dito e o não pensado podem ser articulados. O deslocamento de Boehm consiste em 
considerar que a epistemologia padrão linguística normalizaria os fenômenos imaginais, lançando-os em uma cotidianidade que ignora sua potencialidade; e que a diferença icônica abre o pensamento para articular o não pensado da imagem, cum prindo u m a diferenciação imagem/ linguagem equivalente à entre ente/ser na diferença ontológica.

51. Frequentemente ligada à Escola de Viena e a nomes como Heinrich Wölfflin e Alois Riegl, a "pura visualidade" (pura visibilità) foi um termo cunhado por Benedetto Croce (Fiedler, 2006), quando da divulgação da obra de Konrad Fiedler com Hans von Marées e Adolf von Hildebrand, no início no século XX na Itália (Pinotti, Scrivano, 2006, p. 224-225).

52. Boehm (2009b, p. 249).

53. Boehm (2009d, p. 252253, tradução minha).

54. Estão claras as possibilidades de interpretação da imagem como produtora de um tempo anacrônico - como desenvolveria, a partir de sua conversão benjaminiana, Georges Didi-Huberman em Ce que nous voyons, ce qui nous regarde, de 1992 (O que vemos, o que nos olha, 1998), quando o autor iniciaria a densa reflexão posteriormente organizada em Devant le temps, de 2000 (Diante do tempo, 2016). Boehm (2009b), como Agamben (1977, 1978), definiu essa instância da imagem como articuladora de tempos desde finais dos anos 1970. O tema foi reorganizado por Keith Moxey (2013a) como a betecrononicidade da imagem, uma categoria de redefinição do próprio regime de historicidade.
Para Boehm a filosofia de Merleau-Ponty fora o primeiro momento no século XX em que ocorreu uma virada filosófica e antropológica fundamental. Ali teria sido também, em alguma medida, o primeiro capítulo da virada icônica como uma proposta epistemológica efetiva. Ela era contemporânea da reflexão de Jean-Paul Sartre sobre o imaginário e a subjetividade e do olhar por Jacques Lacan sobre o olhar. Contudo, interessava a Boehm a ideia de que a imagem tinha um traço material e uma presença física, a qual não é contemplada pelas teorias da subjetividade de Sartre ou Lacan. 60

No famoso texto O retorno das imagens, Boehm lançou o termo iconic turn/ ikonischen wendung ${ }^{6 l}$ e sistematizou de forma programática a noção de "diferença icônica". Esta dependia diretamente da materialidade da imagem dotada de potência afetiva e cognoscitiva externa à linguagem. $\bigcirc$ texto de 1994 era a introdução da coletânea alemã Was ist ein bild? (título que pode ser traduzido por "O que é uma imagem?"). ${ }^{62}$ Naquele texto foram repetidas reflexões de estudos anteriores, e, além de visitar os trabalhos de Fiedler e Merleau-Ponty, o autor resenhou com mais atenção as obras de Sartre, Lacan e Ludwig Wittgenstein.

Was ist ein bild? ${ }^{63}$ fora concebido como uma coletânea para apresentar de forma sistemática uma fortuna crítica capaz de formular uma nova abordagem das obras visuais e imaginais; contava com textos clássicos de Merleau-Ponty, Lacan, Gadamer e Imdahl, além de Arthur Danto, Meyer Schapiro, Michael Polanyi, Elmar Salmann, entre tantos. Ou seja, Boehm apresentava e organizava uma discussão no primeiro capítulo de uma coletânea, a qual, por sua vez, contava com alguns dos textos centrais sobre as problematizações do olhar (Lacan e Merleau-Ponty), ${ }^{64}$ a representação (Gadamer), aspectos semióticos da imagem (Schapiro), ${ }^{65}$ a relação entre imagens e cognição (Polanyi), ${ }^{66}$ as definições de iconicidade (Imdahl), a relação entre transparência e opacidade nas imagens (Danto), ${ }^{67}$ e assim sucessivamente.

A publicação, em termos teórico-disciplinares, inscrevia o campo bem como delimitava seus precursores húngaros, franceses, alemães e anglosaxônicos, definindo uma versão da tradição da "ciência das imagens". Na abertura do texto-programa, tomando diretamente a metáfora de Richard Rorty sobre a virada linguística, Boehm afirma:

Queremos caracterizar o retorno das imagens, que a partir do século XIX ocorre em vários níveis, como uma virada icônica. Este título alude naturalmente àquela virada que se completou a partir do fim dos anos 1960 sobre o nome de "linguistic turn". É possível falar, nestes termos em uma "iconic turn"? $\bigcirc$ aplicar-se em condição de linguagem não exerceria uma função similar para os pressupostos das imagens? A pergunta "o que é uma imagem?" 
tem a sua força disruptiva e a sua base efetiva neste processo de história da ciência? $\mathrm{Na}$ sua forma radical, a orientação linguística sustentava que todas as questões da filosofia fossem questões de linguagem. Dito de forma genérica: isso mostrava como o motivo último de todo argumento consistisse não em um ser supremo, em um Eu transcendental ou na reflexividade da autoconsciência, mas sim nas regras da linguagem. ${ }^{68}$

Boehm invoca o pressuposto insustentável de que o mundo seria definido pela linguagem e propõe um direcionamento em prol das imagens. Sua tese era que a experiência da imagem definia a cognição humana e social tanto quanto a linguagem. $O$ texto merece ser seguido de perto: para desmontar a primazia da linguagem mobiliza inicialmente as Investigações filosóficas de Wittgenstein. A entrada em cena dos jogos de linguagem de Wittgenstein não deve ser subestimada, porque na mesma medida em que este autor apontava os problemas filosóficos como problemas linguísticos mal formulados, as "metáforas" dos jogos ou das semelhanças de famílias (elas próprias uma noção imagética) usadas pelo filósofo austríaco, segundo Boehm, evidenciam os jogos icônicos da filosofia, a qual caminharia para uma fratura ao evidenciar, na própria reflexão sobre a linguagem, a resistência à sua supremacia tal como defendida por Rorly. $\bigcirc$ caminho de Boehm pelas ideias de Fiedler, Wittgenstein, Merleau-Ponty e Lacan servia para colher sinais de que a reflexão filosófica do século XX apresentava uma diferenciação entre imagem e texto, "entre" decodificação linguística " $e$ " olhar. Todo o debate filosófico seria apenas uma introdução para a importante ideia de diferença icônica.

A diferença icônica conceituava o que tornava uma imagem possível, questão retomada em $O$ retorno das imagens, ${ }^{69}$ tífulo irônico, uma vez que sua tese é que as imagens sempre estiveram aqui como uma sombra encoberta pela própria linguagem. $\bigcirc$ "retorno" neste caso seria a própria virada icônica, na qual se evidencia que as imagens jamais estiveram ausentes. Qual seria a definição de diferença icônica, aquela que permite definir o ganho heurístico da "virada visual"? Segundo Boehm, haveria um "lugar nativo de todo sentido de imaginal": 70

Aquilo que se faz encontrar como imagem se baseia no contraste fundamental, aquele entre a superfície que podemos colher com um golpe de olhar e tudo que aquela inclui como elementos internos.71 A relação entre o todo intuitivo e aquilo que este contém quanto às suas determinações singulares (da cor, da forma, da figura, etc.) foi de algum modo otimizada pelo artista. [...] [A diferença icônica é] uma potência ao mesmo tempo visiva e lógica, a qual marca a peculiaridade da imagem, que pertence inevitavelmente à cultura material; ela está inscrita de modo completamente irrenunciável na matéria, deixando, porém, emergir um sentido que transcende toda a realidade factual. ${ }^{72}$
55. Novamente Aby Warburg inspirava um eixo historiográfico e epistemológico de reflexão sobre a relação entre imagem e memória, o qual fora pioneiramente articulado no Instituto Warburg na Arte da memória de Frances Yates, publicado em 1964 (2007). Paolo Rossi, (2004) ainda antes de Yates, no ano de 1959, publicou na Itália sobre o mesmo tema, o seu Chave universal.

56. Belting (2005).

57. O subtexto é que os traços icônicos forçam a mente a produzir imagens, na mesma medida em que a mente as produz de maneira a fazê-las funcionar em formas socialmente variadas.

58. Boehm (2009b).

59. Ibid., p. 237.

60. A imagem para Boehm não é apenas o anteparo psíquico que rasga o olhar, para falar com Lacan, mas uma coisa-presença que está na raiz do próprio olhar.

61. Boehm (2009a).

62. Boehm (1994).

63. Ibid., 1994.

64. Dois textos sobre o olhar: de Lacan, Le séminaire, livre XI: les quatre concepts fondamentaux en psychanalyse, em 1964 (O Seminário, 1985) ; e de Merleau-Ponty, Le doute de Cézanne em Sens et NonSens, publicado em 1948 (texto A dúvida de Cézanne, em O olho e o espírito, 2004).

65. O conhecido texto $\mathrm{On}$ some problems in the semiotics of visual art, publicado por Schapiro em 1970 (1973). 
66. Texto What is a painting?, publicado por Polanyi (1970)

67. Tradução para o alemão de um dos textos seminais da estética contemporânea: Depiction and description (1982).

68. Boehm (2009a, p. 42, tradução minha).

69. Boehm (2009a).

70. Ibid., p. 58. No trecho em italiano "il luogo nativo di ogni senso immaginale", o termo immaginale, opção do tradutor Nicol Mocchi, é traduzível por imaginal em português. Imaginal/ immaginale são termos de origem latina (imaginalis), presente em Santo Agostinho, remetendo especificamente à imagem $\mathrm{e}$ não à imaginação, como o galicismo "imagético". A solução foi proposta pelo tradutor Artur Mourão para se referir a alguns usos de bild na obra Das Echt Bild, de Hans Belting, publicada em Portugal como $A$ verdadeira imagem (Belting, 2011, p. 12, rodapé). Neste artigo, imaginal se refere à imagem (picture), enquanto imagético se refere à imaginação.

71. Tal proposta difere do simples contraste figurafundo, afirmado por Gian Paolo Caprettini (1994), segundo o qual, por exemplo, em uma operação pragmática recorta-se em um contorno "visualmente aquela imagem do fundo, pondo em relevo aquele dado num horizonte" (p. 180). A distinção figurafundo é uma das formas e elementos que atuam na diferença icônica, mas em si, esta seria definida por Boehm em função da troca entre olhar do todo-imagem no seu interno, e não do seu contraste com o fundo do qual a imagem parece se destacar. Em suma, o fundo
A diferença icônica é a base antropológica pela qual todas as manifestações visuais são montadas. Ela é uma diferença de potência cognoscitiva não linguística e matriz afetiva. Como diferença específica no trabalho cognoscitivo humano, surge da faculdade de "estilizar o campo perceptivo móvel do ver cotidiano com as suas aberturas marginais e sua adaptação flexível em novas situações, em um campo imaginal circunscrito e estável, e configurá-lo como obra". ${ }^{73}$ Seus vínculos com a cultura material evidenciam o caráter de demanda de materialização daquilo que se pensa, conhece e sente como imagem. Recortando o/do mundo em forma imaginal, aquele fornece por meio de objetos/situações/lugares/suportes os corpos visivos das imagens. Estas possuem, portanto, um caráter presencial e sensorial - mesmo quando são construídas como textos. As diversas implicações desse conceito estão fora do escopo deste artigo, mas basta dizer que para Boehm a diferença icônica, como resultado de uma faculdade antropológica, não significa o nivelamento das experiências com imagens, mas a especificação teórica do porquê as expressões e práticas imaginais e visuais humanas devem ser investigadas em suas próprias condições ontológicas-antropológicas e histórico-culturais e não apenas como capazes de ser reduzidas ao fenômeno linguístico.

Em Boehm, portanto, a diferença icônica garante que imagem e olhar (processo produtor de imagem) possam especificar alguns fenômenos culturais como formas cognoscitivas e afetivas específicas que não foram contempladas pela virada linguística, tornando, de algum modo, mal focadas as reflexões sobre o mundo ser texto/linguagem ou um problema linguístico mal compreendido. A rigor, trata-se de entender que a imagem é "produção do conhecimento e afecções" (não de saberes ou discursos $)^{74}$ e que as formas (sociais) de sua produção delimitam, em todas as culturas - mas cada qual com suas singularidades históricas e sociais - a distribuição, o acesso, a hierarquia e a organização do mundo como conhecimento e afeto. Para Boehm, as imagens não são, portanto, apenas veículos de um conteúdo semântico ou ideal, mas também, como já dito, matrizes de afetos. Isso implica considerar analiticamente a questão da imagem pela sua "intensidade", a qual não pode ser circunscrita em formas categoriais ou semióticas. Em suma, a perspectiva de Boehm aponta que a eficácia das imagens não está localizada apenas na ordem tradicional dos saberes, mas no pathos, evidenciando seu elemento inquietante. Emmanuel Alloa ${ }^{75}$ diz isso de outra forma, quando afirma que a imagem possui um caráter a-tópico e subjuntivo, uma vez que entre um "isso foi" que hipoteticamente representaria, e um "isso nunca será", que hipoteticamente virtualiza, a imagem abre espaços dos possíveis.

Instrumento/forma de conhecer/conhecimento/consciência e matriz de afeto, a imagem define formas próprias e sensoriais do mundo que emergem 
singularmente em interminável jogo com a linguagem. A virada icônica tornou óbvia a premência da indagação filosófica, histórica e psicológica de sua importância. Ela produz uma revisão não apenas do presente, mas de todo o passado cognitivo da humanidade, demandando a reescrita da história por meio daquilo que, talvez, se pudesse chamar de uma antropologia histórica das imagens.

A virada icônica é, portanto, o processo de reconhecimento da importância do imaginal na constituição das relações das pessoas com as coisas e entre si; um ganho heurístico que permite a recondução da hermenêutica das imagens não à velha interpretação de objetos dotados de sentidos a serem "descobertos", mas também a uma dêixis e interpretação do mundo em sua complexidade icônica, valorizando formas complexas de afetos, presenças e significações das coisas-imagens.

\section{MITCHELL: DA DÚVIDA DA IMAGEM À VIRADA PICTÓRICA}

Conhecido no Brasil como criador da noção de virada pictórica, que mais tarde foi "corrigida" como virada visual por Martin Jay, Mitchell é sem dúvida o expoente estadunidense dos estudos visuais e propôs uma revolução na abordagem das imagens nos séculos XX e XXI. ${ }^{76}$ Sua nova iconologia dialoga com a tradição da história da arte, da crítica literária, da filosofia da linguagem, das teorias da arte e semiótica, reorganizando a noção de Panofsky acerca de um processo de crítica iconoideológica interdisciplinar. ${ }^{77}$ Ao contrário de Boehm, mais afeito a certa fusão da hermenêutica/fenomenologia da imagem como "ciência da imagem", Mitchell está diretamente ligado ao impacto da virada linguística e à afirmação do chamado pós-estruturalismo no mundo anglo-saxão.

Bacharel pela Michigan State University em 1963, e PhD em literatura em 1968 pela Universidade Johns Hopkins, Mitchell publicou um estudo seminal sobre o poeta William Blake. ${ }^{78}$ Em 1978 se transferiu para a Universidade de Chicago, onde trabalhou em um grupo de pesquisa sobre literatura e arte que receberia visitas de inúmeros estudiosos, entre eles, Gayatri Spivak. Naquele mesmo ano Mitchell assumiu a edição da revista Critical Inquiry, que se tornaria uma das principais revistas dos EUA sobre estudos das imagens, junto de outras publicações, como October e Representations, fundadas respectivamente em 1976, por Rosalind Krauss, Annette Michelson e Jeremy Gilbert-Rolfe, e em 1983, por Svetlana Alpers ${ }^{79}$ e Stephen Greenblatt. ${ }^{80}$

Sua formação como estudioso da literatura permitiu-the refletir sobre a relação entre palavra e imagem no romantismo a partir de William Blake ${ }^{81}$ e aproximar-se das tradições da retórica e do positivismo lógico. No estudo sobre não cria a figura, mas quando uma figura cria o seu fundo interno, ela faz emergir suas fronteiras com o fundo externo no qual se encontra.

72. Boehm (2009a, p. 58-59, tradução minha).

73. Ibid., p. 59.

74. Distingue-se conhecimento e saber: segundo Michel Foucault (2012), o saber faz parte do eixo prática discursivasaber-ciência. O saber surge como prática discursiva definida, mas é menos estrito do que os discursos, uma vez que designa um conjunto ordenado e sistêmico de enunciados, englobando, além dos enunciados, as técnicas utilizadas para conseguir as enunciações e marcando lugares definidos de poder. O conhecimento trabalha no eixo consciênciaconhecimento-ciência e não respeita simplesmente aos circuitos ordenados de enunciados, mas conflui para viabilizar as enunciações, podendo ter suportes variados, formas não linguísticas e ser composto de práticas não discursivas.

75. Alloa (2012).

76. Cf. Meneses (2012). Há poucos textos traduzidos de Mitchell para o português, destacando-se Mitchell (2015). Há uma entrevista disponível em português (Mitchell, 2009a).

77. Isso torna sua reflexão sobre a iconologia de Panofksy mais coerente do que a batalha anti-hegeliana de Didi-Huberman (1990, 2016), por exemplo, em seu exorcismo do espectro de Panofsky. Ao destruir as bases teleológicas dos estudos da imagem com pretensões kantianas do fundador da iconologia novecentista, Didi- 
Huberman homogeneiza a obra do historiador, cujas potencialidades são transformadas em meras contradições diante das pretensões do telos panofskiano. Já Mitchell (1994) explora as frestas em relação com os "pecados kantianos" de Panofsky para fazer os estudos das imagens produzirem algo novo.

78. Mitchell (1983).

79. Alpers (1996).

80. Krauss e Michelson assumiram a October após dissidências na Artforum, revista de destaque no debate sobre artes contemporâneas nos EUA na época. Importa observar que, apesar da diferença de anos entre as publicações, no primeiro número de October aparecia em inglês o texto Isto não é um cachimbo, de Foucault (2005), assim como no primeiro número de Representations era publicada a importante resenha de Alpers (1983) sobre as interpretações antológicas do quadro de Velázquez, As Meninas, entre elas a de Foucault. Destaque-se a presença do estruturalismo e seus desdobramentos como pósestruturalismo nos EUA em todas essas publicações.

81. A tese de doutoramento de Mitchell (1983) foi sobre as relações entre imagem e metáfora na poesia de Blake, relacionado diretamente às figurações do pintor para a Divina Comédia.

82. Mitchell (1983, p. 79, tradução minha).

83. Publicado pela Critical Inquiry na primavera de 1980, com contribuições de Elizabeth Abel, Leo Steinberg, John Searle, Rudolf Arnheim, entre outros. No mesmo ano gerou-se um volume mais
Blake o autor já apontava que as ilustrações do poeta estabeleciam uma relação indireta com seus poemas, inclusive quando criavam conflagrações e tensões que desviavam do próprio texto, o que só ocorria pelas especificidades conferidas pelo poeta na composição das próprias imagens à medida que a "figura é colocada em um ambiente "elementar" de alguma imagem natural básica como fogo, água, nuvens, vegetação, ou pedra". 82 O trabalho de Mitchell sobre Blake refletia acerca da independência entre imagens e poesia e das possibilidades que emergem da interconexão entre ambas de maneira a ampliar o campo poético como campo dialético entre visível e enunciado, entre palavra e imagem.

Em 1979 Mitchell organizou o seminário sobre "linguagem das imagens" a partir da Critical Inquiry, quando se debruçou sobre o conceito de espaço na literatura, elaborando a noção de "ícones verbais" - formas icônicas cujo potencial metafórico/imagético é fundamental para entender o funcionamento dos textos. ${ }^{83}$ Ali ele já postulava uma primeira proposta de iconologia sobre a leitura como experiência literária e a imagem como experiência fraturada na linguagem. A reflexão fulcral de Mitchell sobre as formas visuais de alguma forma está condensada no texto seminal What is an image?: 84

Meu propósito é sondar o que Wittgenstein chamou de "jogos de linguagem" que nós jogamos com a noção de imagens, e sugerir algumas questões históricas sobre as formas históricas de vida que estes jogos sustentam. Não me proponho a produzir uma nova ou melhor definição da natureza essencial das imagens, mas somente examinar algumas imagens e obras de arte específicas. $\bigcirc$ meu procedimento será examinar alguns dos modos pelos quais usamos a palavra imagem em um número de discursos institucionalizados - particularmente como crítica literária, história da arte, teologia e filosofia - para criticar os modos pelos quais essas disciplinas fazem uso de noções de imagem emprestadas de suas vizinhas. $\bigcirc$ meu objetivo é evidenciar os modos pelos quais a nossa compreensão teórica das imagens se baseiam em práticas sociais e culturais em uma história que é fundamental para a nossa compreensão não só das imagens, mas também do que a natureza humana poderia ser. ${ }^{85}$

A longa citação é um programa de pesquisa: a investigação das formas discursivas de pensar e tratar as imagens; o fato de que antes de fenômeno puro, a ligação entre imagem e discursos não é questão de natureza, mas da forma como as práticas sociais e culturais tomam vida social; a importância dos jogos de linguagem na consideração de que uma imagem é uma alteridade, assim como a linguagem só o é pelas imagens que ela mobiliza; a necessidade de compreender este processo numa história (e genealogia, acrescentaríamos); a imagem como forma de vida, princípio ao qual Mitchell dará desenvolvimento a partir de meados 
dos anos 1990. A princípio isso parecia indicar que para compreender a história das imagens, a história dos textos se tornaria o primeiro movimento fundamental, mas o objetivo de Mitchell era evidenciar a impossibilidade de estabelecer a harmonia entre linguagem e imagem, as quais se perturbam e exigem posicionamentos mútuos. No caso do discurso verbal, tais posicionamentos são pensáveis a partir dos jogos/confrontos na linguagem.

A princípio o recurso a Wittgenstein poderia parecer contraditório no programa de um dos teóricos de uma virada pictórica, principalmente se se conta que Mitchell menciona com frequência o filósofo austríaco ou outro conhecido autor da virada linguística, Michel Foucault, como referência quando afirma que a imagem é o equivalente da "ordem das coisas", como chamou atenção Karl Schøllhammer. ${ }^{86}$ Os jogos são estratégias para ceder ou resistir à transformação das imagens em ideias; são como a caverna de Platão ou a noção de ordem das coisas de Foucault, todos "hiperícones" ou torções da linguagem para contemplar o "pictórico".

Aqui o princípio era - como na reflexão de Boehm - de que o jogo de linguagem tem um funcionamento imagético, ou seja, elabora imagens que não estão contidas apenas em sua dimensão linguística, mas contrasta sem se separar da relação entre imagem e discurso. Para Mitchell, os modelos montados a partir da linguagem são transformados em modelos pictóricos. Mas se para Wittgenstein (e Foucault), por exemplo, a linguagem era opaca ${ }^{87}$ e os conteúdos eram funcionalizados pelos usos, para Mitchell os "conteúdos" são as relações de representações produzidas entre imagens e textos, as quais incorporam as relações sociais e culturais que são produzidas com" eles.

A rigor, Mitchell afirma que a imagem é um campo de conflagração das tensões sociais, produzindo novas tensões por sua alteridade evidente em relação à linguagem, mas da qual não pode jamais se libertar - e vice-versa. A compreensão da imagem só é possível "na consciência da irredutível coexistência e convergência do visivo e do verbal em ambos os sistemas comunicativos e semióticos", 88 no confronto entre as diferenças visuais e textuais, que são sempre diferenças de cunho social. A presença da semiótica e do positivismo lógico na obra de Mitchell faz-se sentir desde o início em sua abordagem como uma póssemiótica. Em lconology, por exemplo, o texto sobre Nelson Goodman revela o problema padrão do qual parte Mitchell: para Goodman tanto imagens como textos são convencionalizados (no que Mitchell concorda), uma vez que as palavras e imagens são convenções (etiquetas) linguísticas \& visuais na construção da realidade; mas para Goodman a etiqueta visual seria, de alguma forma, subsumida pelas etiquetas verbais colocadas em ação, na medida em que estas mobilizam amplo, publicado com o mesmo título (Mitchell, 1980), contando com novas contribuições, entre elas, de Nelson.

84. Mitchell (1984).

85. Ibid., p. 504, tradução minha.

86. Cf. Schøllhammer (2001). Duas observações de cunho bibliográfico poderiam ser úteis: a primeira é que o impacto de What is an image? está ligado a sua republicação no livro-programa Iconology, lançado em 1986 (Mitchell, 1984; 1986a). Neste livro o autor acrescentou pequenos prólogos a cada seção, e especificamente naquele intitulado "The idea of image" (1986b, p. 5-6) existe uma rápida observação na qual Mitchell chama os "jogos de linguagem" de Wittgenstein de hiperícone, ou seja, modos pelos quais as imagens se duplicam, pelos quais se representa o ato de representar ou como se figura a prática de figuração. A segunda observação diz respeito ao papel de Foucault, uma vez que a ideia de que "a imagem não é simplesmente um tipo particular de signo, mas o princípio fundamental do que Michel Foucault chamou de 'ordem das coisas". (Mitchell, 1986b, p. 11) é um acréscimo de 1986 ao texto de 1984 , junto da reflexão sobre a teoria platônica e as ideias de Roger Bacon, ampliando, portanto, a dimensão do hiperícone.

87. A oposição opacidade e transparência tornou-se um topos. Na leitura de Martin Jay (1993) sobre Foucault, por exemplo, a linguagem seria opaca e o discurso afastaria a natureza das relações de poder que elas criam. A imagem, em Foucault, seria a forma contrastante que evidencia a opacidade da linguagem. 
Para Wittgenstein, por sua vez, o jogo de linguagem evidenciaria o modo de os filósofos tratarem a linguagem como algo transparente, mas cuja opacidade deve ser realçada a partir do seu uso. Danto reconduziu a discussão a partir do princípio de arte entre transparência e opacidade, questão que foi retomada por Boehm (2009a) e por Alloa (2015). Nossa hipótese é que para Mitchell a linguagem (ou a imagem) não são opacas ou transparentes, mas meios, substâncias intervenientes no resultado cognitivo e afetivo. A leitura de Michele Cometa (2018) segue nessa direção.

88. Cometa (2018, p. 18-19).

89. Embora o "momentoMitchell" em língua inglesa da pictorial turn seja a publicação da coletânea de artigos em Picture theory, de 1994, o texto-programa The pictorial turn viera à luz em 1992, na revista Artforum.

90. Mitchell (1994).

91. Baxandall (1991) publicava seus principais estudos no início dos anos 1970: Giotto and the orators, em 1971; e Painting and experience in Fifteenth Century, em 1972. Alpers publicava Art of description em 1983 (A arte de descrever, 1999). Para uma reconstrução deste contexto, cf. Knauss (2008); Pinotti; Somaini (2016).

92. Mulvey (1983, texto original de 1975). Este é um texto ontológico sobre a reflexão do olhar na segunda metade do século XX. Laura Mulvey voltou ao tema do prazer narrativo em 1989 fazendo uma revisão de suas ideias. Cf. Mulvey, 2005.

93. Cf. Bryson (1983; 1986).

94. Mitchell (1991) aquelas (no que Mitchell discorda). Para Mitchell a força da etiqueta visual é justamente quebrar a sutura aparente que os jogos da linguagem parecem deixar intactos. Convencionalizados paralelamente, imagens e textos se intrincam em suas diferenças irredutíveis, jamais separáveis.

Esta é a base da nova iconologia de Mitchell. Apropriando-se da abertura produzida por Panofsky, ele postula que textos e imagens servem de guias mútuos na investigação histórica das representações, evitando, contudo, os velhos hábitos hermenêuticos da repressão do que seria específico ao pictórico. Isso só é possível porque a emergência de imagens (pictures) e textos (texts) consiste nas próprias práticas de significação sociais que encarnam as imagens (idea). Essa noção não significa apenas a possibilidade de olhar o mundo usando imagens como objeto do conhecimento, mas que as imagens estiveram em todos os objetos do conhecimento já montados. Assim, implica a necessidade de investigar novamente a história da cultura sob um prisma pictórico - ou imaginal, para retomar Boehm. A "virada pictórica", idealizada por Mitchell em 1992,89 partiu dessa constatação: se a imagem é fundamento da "ordem das coisas", é preciso investigar as coisas de seu ponto de vista e ver como a linguagem se perturba com ela.

Por que, portanto, uma "virada pictórica" defendida no artigo The pictorial turn? 90 Primeiro devemos entender que não era uma indagação solitária e sem precedentes: a reflexão feita por Michael Baxandall e Svetlana Alpers acerca da história social da arte, ${ }^{91}$ a teoria do cinema e a reflexão sobre o olhar, incluindo parte dos estudos feministas como os de Laura Mulvey, ${ }^{92}$ bem como o estudo de Norman Bryson ${ }^{93}$ sobre a relação entre imagem e texto e a visão como algo não natural, além dos trabalhos sobre imagem medieval de Michael Camille, eram interlocutores de Iconology, o livro seminal de Mitchell de 1986. ${ }^{94}$ No fim dos anos 1980, a coletânea Visual and visualty, organizada por Hal Foster, ${ }^{95}$ contava com autores como Martin Jay, Rosalind Krauss, Jonathan Crary e Bryson, e definia um campo de preocupação com a visualidade voltado a novas propostas heurísticas sobre as imagens, uma "virada" não nomeada. ${ }^{96}$

Quando a virada foi nomeada, em The pictorial turn, era pictórica. Em língua inglesa image é a palavra usada para designar a coisa imagética (idea) e picture, para designar o imaginal, a coisa material. Já em What is an image? Mitchell havia destruído a existência essencial da imagem mental como algo correspondente a um mundo pré-convenção. É justamente o fato de uma prática social se encarnar como texto ou como picture que faz as images circularem, mas estas são produzidas dentro dos padrões convencionais historicamente construídos como práticas sociais. $\bigcirc$ paradigma da materialização do 
conhecimento/saber como imagem pictórica sim marcaria a revolução heurística da "virada", porque as imagens pictóricas é que foram secundarizadas pela história da cultura, e a partir do cruzamento das imagens materiais com os textos se poderia revisar essa história.

Em 1994 o autor reuniu várias reflexões sobre as relações entre textos e imagens no volume Picture theory, aberto pelo texto-programa The pictorial turn, e usou o eixo da "meta-imagem" e da "imagem/texto e suas variações" 97 como pedras de toque de um deslocamento da investigação que evidenciavam a existência de uma nova forma de abordar o mundo social e sua constituição ideológica: as ansiedades produzidas como imagens, por imagens e entre imagens e palavras como objetos de uma nova iconologia. O problema teórico evidencia a origem de Mitchell como crítico literário e o próprio fato de que, como chamou atenção Michele Cometa "todos os mais aguerridos defensores da 'virada visual' [...] não podem deixar de colocar no centro da reflexão teórica a questão do confronto entre a dimensão verbal e a dimensão imaginal". ${ }^{98}$ Delimitando o campo, Mitchell distinguia as categorias que são centrais: "imagem/texto" é uma lacuna problemática, uma clivagem ou ruptura na representação construída pela combinação de palavras e imagens; "imagemtexto" designa as composições que combinam imagens e textos; e imagem-texto (com hífen) designa a relação entre o verbal e o visual. A clivagem imagem/texto, por exemplo, estava na raiz de muitos dos jogos de linguagem apontados em What is an image?, mas à luz da coletânea Picture theory 99 ela se torna tópico da virada pictórica e da proposição de um programa iconológico, ou seja, a partir daquele novo momento devia-se abordar o modo como as pictures faziam funcionar as images. ${ }^{100}$

A virada pictórica seria, portanto, um diagnóstico de época pela montagem de um programa de pesquisa. Começando pela proposição da virada linguística, Mitchell avisa que o problema levantado por Richard Rorty tinha a ver com questões específicas do discurso acadêmico e filosófico (notadamente na filosofia, linguística e etnografia), mas a questão das imagens implica no conjunto de transformações complexas que atingem a vida cotidiana e o espaço público, os quais tinham ecos na vida acadêmica. Nesta última ocorria uma pictorial turn, e seus antecedentes filosóficos seriam vários: o positivista lógico Nelson Goodman, que afirma que tudo são convenções e códigos de sistemas simbólicos não linguísticos, sem partir do pressuposto de que a linguagem seja o paradigma base; a investigação fenomenológica europeia sobre a imaginação e a experiência visual; a gramatologia de Jacques Derrida e sua crítica do fonocentrismo e do logocentrismo por meio da investigação dos traços materiais da escritura; ${ }^{101}$ as investigações da
95. Foster (1988).

96. Foi primeiro em língua alemã que surgiu uma antologia organizando o campo intelectual ao redor do princípio de preocupações com a imagem, Was ist ein bild? (Boehm, 1994). Comparar Was ist ein bild? e Vision and visuality (Foster, 1988), por exemplo, permite ver a diferença na Alemanha e nos EUA na definição de campos. No conjunto de Foster, apenas Lacan e Merleau-Ponty, dos constantes em Was ist ein bild?, eram debatidos e citados, enquanto todos os outros autores eram pesquisadores recentes. Nos EUA, as coletâneas sobre cultura visual posteriores a Vision and visuality seguiriam o seu formato, integrando sempre novos pesquisadores. O text-book The visual culture reader, organizado por Nicholas Mirzoeff no final dos anos 1990, destaca-se como mais próximo da proposta alemã. Destaque-se que Mirzoeff pensa o campo da cultura visual a partir da herança dos estudos culturais.

97. Em 2012 o autor defenderia que, se a virada visual era uma relação palavra $\rightarrow$ imagem, tudo só se torna pensável porque existe a distinção estratégica image/picture, ou seja, entre imagem intangivel (image - entidade abstrata que pode ser evocada com uma palavra singular) e a imagem material (picture objeto material ou coisa, o suporte material ou lugar específico no qual aparece uma imagem intangível). Perceba-se a existência da notação lógica na explicitação da ideia: o símbolo $\rightarrow$ significa o mesmo que inclusão e designa a existência de um domínio (palavras) e um contra-domínio implicado (imaginal). A metaimagem seria, por sua vez, uma 
imagem material (picture) na qual uma imagem intangível (image) de outra imagem material (picture) aparece, como por exemplo o quadro As Meninas (1655), de Diego Velázquez.

98. Cometa (2012, p. 23).

99. Mitchell (1994)

100. Aqui está a raiz da crítica de Hans Belting (2003) a Mitchell: segundo o historiador alemão, em Iconology o autor se debruçou sobre textos que descreviam e lidavam com imagens, mas apenas a partir de Picture theory ele se deslocaria no rumo das imagens em si mesmas, tentando definir o que havia de pictórico nas práticas sociais numa real iconologia. Exatamente por isso a antropologia das imagens seria, segundo Belting, uma forma de iconologia. Neste sentido, The pictorial turn seria uma revolução para seu próprio propositor, embora isso já estivesse presente desde o estudo sobre William Blake e em inúmeros artigos após a publicação de Iconology.

101. Observe-se aqui a peculiaridade do uso que Mitchell faz da obra de Derrida, bem diferente do puro-textualista atribuído ao filósofo argelino imaginado no Brasil - principalmente por historiadores brasileiros - ou mesmo por Boehm (2012). O trabalho de Mitchell está marcado pela interpretação de Spivak (2012) na tradução feita pela indiana para o inglês da Gramatologia do filósofo argelino, publicada em 1977 nos EUA.

102. A combinação entre paradigma (campo de compreensão ou episteme do funcionamento do trabalho investigativo) $\mathrm{e}$ anomalia (desvio que o paradigma não contempla, mas que o faz se mover e teoria crítica dos mass media e mídias visuais; as insistências de Foucault sobre o poder/saber e as delimitações do visível e do dizível; e seu mais evidente antecedente, a investigação de Wittgenstein que, num problemático conceito de jogos de linguagem, propunha uma iconoclastia dos conceitos filosóficos como paradoxos da linguagem.

Todos estes expoentes teóricos tratariam de variados graus de ansiedade com as imagens, um "defender-se contra o visual". Essas propostas teriam em comum o fato de que as representações visuais e as imagens materiais seriam um ponto de fricção e desconforto. Tomando a imagem (picture) como o que Thomas Kuhn chamou de "paradigma e anomalia", 102 Mitchell as faz surgir para as disciplinas tal qual surgem para a linguagem, mas sem se identificar com esta: um tipo de modelo de figurar outras coisas e, por fim, um objeto insolúvel. A definição da virada pictórica segue uma proposta epistemológica de investigação:

\footnotetext{
De qualquer forma a virada pictórica é, então, deve ficar claro, não um retorno a mímesis ingênua, às teorias da cópia ou suas correspondentes da representação, ou à metafísica renovada de "presença" pictórica: é uma redescoberta pós-linguística e pós-semiótica da imagem [picture] é como uma interação complexa entre a visualidade, aparelhos, instituições, discurso, corpos e figuração. É a constatação de que os atos de assistir (a visão, o olhar, a mirada, as práticas de observação, vigilância e prazer visual) podem ser um problema tão profundo quanto as várias formas de leitura (decifração, decodificação, interpretação, etc.) e que experiência visual ou "alfabetização visual" pode não ser totalmente explicável no modelo de textualidade. O mais importante, é a constatação de que, embora o problema da representação pictórica [pictorial representation] sempre tenha estado conosco, ele pressiona inescapavelmente agora, e com uma força sem precedentes, em todos os níveis da cultura, desde as especulações filosóficas mais refinadas até as produções mais vulgares dos meios de comunicação de massa. As estratégias tradicionais de contenção já não parecem adequadas, e a necessidade de uma crítica global da cultura visual parece inevitável. ${ }^{103}$
}

Neste trecho, sempre muito citado, o afastamento de Mitchell dos horizontes imediatos da teoria da representação tradicional (mímesis), da fenomenologia (presença) e da hermenêutica tradicional (leitura e interpretação) evidencia o choque de usos de imagens e da constituição da "expectação" em um problema autônomo. A atenção deve ser redobrada para a especificação dos termos: Mitchell usa picture, a imagem material, como definidora de uma grade de experiências, e, ao contrário do que parece a tradução para o português, 104 pictorial representation refere-se a um espectro de artefatos, práticas, usos e materialização de imagens, uma espécie de realização das imagens (images) intangíveis. Por isso o termo inicial empregado por Mitchell 
seria pictorial turn, uma "virada pictórica", a qual cobriria um conjunto de problemas que excedem, embora estejam relacionados, ao problema da leitura de textos, que por sua vez podem contemplar imagens, mas nem sempre pictures. Isso também está relacionado ao projeto maior da iconologia em Picture theory: as variadas considerações sobre as relações entre imagem-texto e imagem/texto e um projeto em que images e pictures são distintas, devendose identificar sua relação com a textualidade como uma das bases da iconologia crítica enquanto crítica ideológica, a qual, ao seguir seu princípio iconológico, sempre pressupõe "uma especificidade não textual das imagens". ${ }^{105}$

A iconologia crítica, por sua vez, faz-se por uma reabilitação do projeto de Panofsky, sem usar, porém, as pretensões kantianas do historiador alemão ou sua ideia de submissão do visual ao textual. Mitchell busca construir sua cena original da iconologia a partir da cena primeira de Panofsky, juntando este com a crítica da ideologia do sujeito soberano de Lovis Althusser. A base da iconologia crítica ou pós-moderna é reagir à repressão das imagens por meio da repressão da linguagem, acentuando a multidimensionalidade da imagem que estaria exemplificada no trabalho pioneiro de Panofsky sobre perspectiva. ${ }^{106}$ A resistência do ícone à linguagem permite articular os níveis sociais de construção ideológica, contemplando campos de ação éticos e políticos.

Se o defeito da iconologia clássica estava na repressão da imagem pelo texto, seu princípio permanece estável na medida em que a nova iconologia, como crítica ideológica, é uma prática que aponta a sutura incompleta entre imagem e texto. Para Mitchell, textos e imagens demandam-se mutuamente como alteridade e complemento. A iconologia almejaria, neste sentido, demonstrar que as imagens acontecem como o "outro" do texto - uma proposta adequada aos tempos de virada pictórica, porque não nega a relação base com a textualização das imagens ou o poder imaginal e imagético dos textos, mas permite localizar as formas de relação entre ambos.

O princípio mais ousado do conceito cunhado por Mitchell foi o de que a virada pictórica ocorreria como uma ansiedade para com as imagens, em uma relação direta com o espaço público. Na coletânea Picture theory o autor tenta demonstrá-lo por meio de investigações das obras de William Blake, Robert Morris, Spike Lee, Oliver Stone e tantos mais. Existiriam diferentes tematizações das imagens no espaço público, e a virada pictórica seria um diagnóstico sobre práticas plurais da relação com as imagens. A nova epistemologia visual, que daria origem no mundo acadêmico aos visual studies, seria apenas um componente dessa ansiedade pictórica em geral. Porém, apenas nos anos posteriores Mitchell conseguiria clarificar o aspecto público dessa ansiedade. talvez até se romper) no mesmo domínio da image/ picture explicaria, na percepção de Mitchell, porque a imagem cumpre funções cognitivas e perturbadoras ao mesmo tempo.

103. Mitchell (1994, p. 16, tradução minha).

104. A expressão "representação pictórica", em português, refere-se principalmente a um tipo de representação em pintura.

105. Cometa (2018, p. 21, tradução minha).

106. Panosfky (1991). 
107. Jay (1993).

108. A tradução adequada de denigration remeteria ao politicamente incorreto (e frequentemente racista) "denegrir" a visão, no sentido etimológico, uma vez que a imagem tem sido associada à luz e claridade na filosofia ocidental, e a iconoclastia da filosofia francesa, em sua imensa maioria teria sido, para Jay, uma operação para demonstrar como o visual e o olhar foram lançados no obscurantismo. Cf. Jay (1993), exemplarmente o capítulo 7 , com a análise da filosofia de Foucault e de Guy Debord. O livro é recheado de sinonímias da difamação do olhar (gaze), da visão (vision), do visual (visual) e do ocularcentrismo (ocularcentrism).

109. Tópico fundamental para Mitchell, a iconoclastia estava na base da reflexão de inúmeros estudiosos, e desde então só tem crescido em destaque. Cf. Belting (2001, original de 1990); Bettetini (2013; 2016); Boehm (2009b); Jay (1993); Latour (2009, original de 2005); Mitchell (1985; 1994; 2011); Mondzain (2013, original de 1996).

110. Bryson (1983); Foster (1988); Jay (1988); Mitchell (1985).

111. Jenks (1995).

112. Foster (1988, p. ix, tradução minha).

113. Brennan; Jay (1996).
INTERMEZZO VISUAL TURN E AVANTE: AS "VOLTAS" DA VIRADA

A fortuna teórica da pictorial turn e da iconic turn demorou mais de uma década para se estabelecer. A republicação de The pictorial turn na coletânea Picture theory por Mitchell, em 1994, gerou ressonâncias em Martin Jay, ${ }^{107}$ atento leitor dos estudos pós-estruturalistas e autor de Downcast eyes, importante estudo sobre o que o historiador da filosofia chamou de escopofilia e a difamação ${ }^{108}$ da visão na filosofia francesa do século XX. Com seu sugestivo título de "olhos rasgados" (que remete a Lacan e Georges Bataille), o livro continha a reorganização histórica da noção de imagem na filosofia ocidental, seguida por análises das obras de Lacan, Althusser, Henri Bergson, Foucault, Debord, JeanFrançois Lyotard e Derrida. A ubiquidade das metáforas visuais na filosofia francesa estaria acompanhada pela sucessiva destruição do valor do visual e das imagens, evidenciadas como opacas. A presença de Mitchell e seu lconology se faz sentir em Downcast eyes, como citação direta, mas também nas reflexões sobre iconoclastia ${ }^{109}$ e nas operações de repressão das imagens por parte do discurso da filosofia francesa.

A publicação de Downcast eyes criou uma reação imediata na revisão dos paradigmas de visão e visualidade, cuja problemática, como vimos, já havia sido aberta nos EUA por Bryson, Krauss, pela iconologia de Mitchell e pela coletânea Vision and visuality, na qual constava o texto Scopics regimes of modernity, de Martin Jay, com a tese dos "regimes escópicos", que se tornaria ubíqua no debate dos anos 1990. ${ }^{110}$ Os primeiros compêndios sobre cultura visual, como Visual culture, organizado por Chris Jenks, ${ }^{111}$ contemporâneo de Picture theory, nos EUA, são profundamente marcados pela reflexão de Jay, que seguia a problematização produzida no seminário de 1988 organizado por $\mathrm{Hal}$ Foster. Nas palavras do próprio Foster:

A visão é também social e histórica, e a visualidade envolve corpo e psique. Todavia, não são idênticas: aqui, a diferença entre os termos assinala uma diferença no interior do visual - entre os mecanismos da visão e suas técnicas históricas, entre o dado da visão e suas determinações discursivas - uma diferença, muitas diferenças, entre de que modo vemos, como somos capazes, autorizados ou levados a ver, e como vemos esse ver ou o não visto dentro dele. ${ }^{112}$

Em Vision in context, de 1996 organizado por Jay e Teresa Brennan, 113 aparecia o primeiro "aceite" de destaque da pictorial turn de Mitchell. Já no primeiro parágrafo da introdução, Jay, partindo da tradição crítica, avaliava que uma 
concepção de turn contemplava as noções de "visual" e "visualidade", com suas respectivas práticas e experiências, deslocando aquilo que Mitchell havia definido ao redor das pictures (imagens materiais):

A nova fascinação com modos de visão e os enigmas da experiência visual evidente em uma rede variável de campos pode bem ser tomada como mudança paradigmática no imaginário cultural de nossa época. $\bigcirc$ que foi chamado de "the pictorial turn" veio justamente para suceder a "virada linguística" tão fortemente proclamada no século XX. O modelo de "leitura de textos", o qual serviu produtivamente como metáfora mestra das interpretações pós-objetivistas dos mais diversos fenômenos está dando lugar para modelos de espectorialidade e visualidade, os quais recusam ser descritos em termos estritamente linguísticos. O figural é resistente à subsunção sob a rubrica da discursividade; a imagem demanda seus modos únicos de análise. ${ }^{114}$

autor continuava citando as contribuições de uma série de estudiosos para concluir que a virada pictórica (ele conservava o termo apesar de fazer o deslocamento) é mais imprevisível do que se imagina e se baseia na "investigação das teorias sobre a visão, culturas visuais em geral e artefatos visuais específicos" . 115 Na conclusão da coletânea, ${ }^{116}$ Brennan consolidou o movimento teórico proposto por Jay e passou a usar a expressão visual turn, introduzindo o deslocamento a partir do qual ficará ainda mais famosa a cultura visual. Brennan retomou o problema do olhar ${ }^{17}$ a partir de Lacan, e refletiu que conceber a visão como construída socialmente faria parte da visual turn do final do século XX, uma vez que houve visual turns anteriores, das quais a autora destaca as ocorridas nos séculos XVIII e XIX. Seu texto segue a mesma intuição de Mitchell, para quem as viradas visuais corresponderiam às ansiedades relacionadas com imagens. Apropriando-se da discussão da Lacan e Jay, Brennan propunha que a virada visual é uma chave de revisão da história da subjetividade e modernidade ocidentais. A mirada de Jay e Brennan propunha uma perspectiva histórica sobre como uma sociedade se produz por meio de imagens e do olhar, e evidencia a direção que tomaram, nos EUA, as publicações relacionadas aos estudos visuais.

Em 1996 a revista October, com um editorial avesso às propostas emergentes, apresentou um questionário a muitos autores (Thomas Conley, Anne Friedberg, Jonathan Crary, Susan Buck-Morss, Svetlana Alpers, Thomas Gunning, Michael Ann Holly, Martin Jay, Stephen Melville, Christopher Wood etc.), o que se tornou uma marca daquele momento. ${ }^{118} \mathrm{Se}$ Jay ${ }^{19}$ apontava a possibilidade de tratar o visual e a visualidade com cuidado para não cair no relativismo, no mesmo número e discutindo o texto de Mitchell que ali também era publicado, What do pictures really whant?, 120 Krauss destacava a falta de originalidade
114. Jay (1996, p. 3, tradução minha).

115. Ibid., p. 9, tradução nossa.

116. Brennan, 1996.

117. Como já dissemos, o olhar é um tópico central na escrita da história da articulação da cultura visual e da virada visual. Brennan cruzava, por exemplo, a reflexão feminista sobre o olhar, a psicanálise e a história da modernidade (Brennan, 1993). Foi em Vision in context, porém, que se configurou a virada visual segundo as chaves fornecidas pela psicanálise (Id., 1996). O debate sobre a formação da modernidade (Crary, 2012; Gunning, 1991) como tópico de estudo, que incorporou tanto a teoria crítica (em especial de Benjamin) como a teoria do dispositivo francesa (de Foucault), foi um dos campos de emergência dos estudos sobre o visual e a visualidade, que são um capítulo à parte da virada visual, além dos limites de nossa reconstituição no momento. Cf. Jay (1988; 2003-2004).

118. As perguntas (Mitchell, 1996, p. 25) evidenciavam uma interpretação singular dos mais destacados trabalhos na direção dos estudos visuais, por exemplo: o projeto interdisciplinar da cultura visual era baseado num modelo antropológico - o que significava dizer que era um modelo sincrônico e sem diacronia; a cultura visual se basearia em um conceito de imagem desmaterializada, ideal e marcadamente fantasmática. Anos depois, Dikovitskaya (2005) ressaltou a nítida resistência daquele dossiê de October. Outra avaliação pertinente é a de Costa e Schiavinnato (2016, p. 1619). Mitchell (2002) retomou 
ironicamente este dossiê no artigo Showing seeing.

119. Jay (1996).

120. Mitchell (1996). Curiosamente, o autor não aparece entre os consultados.

121. Krauss (1996, p. 96).

122. O esforço de Krauss era demonstrar que a ideia de Lacan do inconsciente como linguagem (invocada, segundo a autora, erroneamente por Mitchell em Pictorial turn) evidenciava ironicamente o papel da imagem no inconsciente. A solução de Lacan foi, segundo Krauss, evidenciar que a identificação do sujeito não ocorria com o real, mas com a imagem (o anteparo) que lhe servia de defesa contra o real traumaticamente ausente. Krauss sugere que os estudos visuais forçavam como premissa o que em Lacan era um diagnóstico: o sujeito se identificar com a imagem era algo a ser compreendido na história clínica, e a consequência maior seria que "tudo" (as reações e relações do sujeito) era subjetividade. Se os visual studies caminhassem nessa direção, cairiam numa armadilha: purificar a imagem da linguagem, repetindo o mito modernista, e identificar o mundo com as imagens. Não precisamos ir muito longe para compreender que a antipatia de Krauss às novas propostas levou-a a conclusões forçadas.

123. Mirzoeff (1999, p. 6).

124. Respectivamente Mirzoeff (1998; 1999). Ressalte-se que na primeira edição de An introduction to visual culture, Mirzoeff usava a expressão picture theory (p. 6) para designar o que Mitchell chamava de pictorial turn. Mirzoeff resume o trecho de The dos estudos de cultura visual, os quais seguiam a falta de originalidade dos estudos culturais, que ironicamente se concebiam como revolucionários. ${ }^{121}$ Krauss conclui que a proposta da pictorial turn seria uma atualização dos mitos modernistas, em especial aqueles referentes às purezas das formas plásticas, e apresentaria sensivel falta de historicidade, chegando a usar uma interpretação heterodoxa da teoria de Lacan da imagem-como-identificação do sujeito, ${ }^{122}$ uma chave comum, segundo ela, também dos estudos culturais. Os estudos culturais estariam na base da picture theory de Mitchell e da virada pictórica. Segundo Krauss, rejeitar a linguagem em prol de um conceito de imagem-diferença com a qual se deve identificar o espectador significava cair num equívoco modernista caduco, repetido pelos estudos culturais.

Tentando construir uma tradição legítima a partir da consolidação dos estudos culturais, subalternos e pós-coloniais, em dois livros sucessivos Nicholas Mirzoeff retomou a expressão pictorial turn para evidenciar a constituição do campo de pesquisas dos visual culture studies. ${ }^{123}$ Em The visual culture reader e An introduction to visual culture a expressão pictorial turn ${ }^{124}$ foi atrelada à noção principal de cultura visual (visual culture) no sentido da construção social de eventos por meio da visualização cotidiana. Importa mencionar que as definições propostas por Mirzoeff, construídas a partir dos cruzamentos entre as ideias de Erwin Goffman, Foucault e Michel De Certeau, ligavam a formação da cultura visual na sociedade industrial com a revolução da produção de saberes e práticas sociais que coincidem com o que o autor chamou de "era fotográfica". Ficava claro, portanto, que para Mirzoeff a pictorial turn defendida por Mitchell era um evento sócio-histórico relacionado com dispositivos de visualização transformadores da vida social: em suma, a virada visual se confundiria como experiência constitutiva da formação da cultura visual no século XIX em diante. Apesar de mencionada uma única vez em An introduction..., para marcar a mudança radical no campo da experiência cotidiana, a virada é a metáfora absoluta base da argumentação da Mirzoeff. ${ }^{125}$

No início dos anos 2000, Jay ${ }^{126}$ tentou reescrever a história da virada visual a partir das preocupações éticas com o relativismo cultural dos estudos culturais e reivindicou para a tradição crítica a primeira formulação da virada visual. Jay tratava a experiência histórica com as imagens como núcleo da questão comum da cultura visual, não apenas relacionada com a modernidade industrial do século XIX, sendo a visual turn uma tomada de consciência sobre a constituição histórica visual da sociedade. Nessa reescrita da história dos estudos visuais e da virada visual, naqueles anos e nos posteriores, Jay ignorava os estudos alemães e mencionava apenas franceses. Demarcação de território acadêmico, aquele texto mostrava um confronto de tradições intelectuais no cenário estadunidense. ${ }^{127}$ 
$\bigcirc$ ponto de inflexão foi produzido pela publicação de Dikovitskaya, ${ }^{128}$ que no próprio título (Visual culture: the study of visual after the culture turn) situa a pictorial turn de Mitchell como a visual turn de Jay, ambas como desdobramentos da culture turn iniciada antes. Retomando as entrevistas da October de 1996 e inserindo sua própria avaliação, Dikovitskaya tentava ampliar os estudos sobre cultura visual ao incorporar as múltiplas possibilidades da virada visual, para além da crítica, segundo ela de matriz marxista, contida na October. Ao fazê-lo, Dikovitskaya atribuía uma origem ao termo e consolidava um direcionamento da virada pictórica americana para a virada visual e a imposição da cultura visual.

Tais debates dizem respeito à definição de um campo acadêmico estadunidense. A discussão da Bildwissenschaft nos EUA, contudo, surgiu como uma abertura produzida pela publicação de textos de estudiosos alemães nos EUA e de divulgação de estudos estadunidenses na Alemanha. Talvez o momento fundante tenha sido a publicação de A neglected tradition? Art history as 'Bildwissenschaft', na Critical Inquiry, de Horst Bredekamp, 129 a primeira entrada da "ciência das imagens" e da iconic turn nos EUA, produzindo uma aproximação entre dois ambientes acadêmicos. $\bigcirc$ próprio Mitchell já havia chamado atenção à iconic turn em seu artigo Vital signs anos antes, 130 no qual ele estabelecia uma sinonímia entre visual, iconic e pictorial turn como abordagem comum, citando Bredekamp, Boehm e Belting. Por outro lado, a admissão da sinonímia parece revelar um pouco a fortuna acadêmica da redefinição de Jay/Brennan da "virada".

Em 2005, também na Critical Inquiry, foi publicado o texto-programa da antropologia da imagem de Belting (Image, medium, body: a new approach to iconologyl, versão ampliada e reescrita do primeiro capítulo da sua BildAnthropologie, publicado na Alemanha em 2001. ${ }^{131}$ Naquele texto Belting aproximava seu esforço da iconologia de Mitchell a partir da tradição da ciência da imagem. Ali marcava sua distinção da obra de Boehm, que tinha uma perspectiva mais ontológica para tratar a imagem, enquanto a de Belting era mais historiográfica e se aproximava diretamente dos visual studies por meio da chave da iconologia. Na conclusão do artigo, afirmava que se originalmente a iconologia fora restrita apenas às artes, a "nova iconologia desenhava uma ligação entre imagens, em geral, mas por meio da reintrodução do corpo, o qual havia sido marginalizado pela fascinação com as mídias". ${ }^{132}$ A nova iconologia era, portanto, uma antropologia das imagens por meio da sua migração entre corpos e mídias. Mitchell construiria a consciência ampla deste debate a partir daquele mesmo ano, o que resultaria em um artigo no qual o próprio Mitchell reavaliava as noções de cultura visual (visual culture) e estudos visuais, respondendo críticas e fazendo novas considerações. ${ }^{133}$ pictorial turn, no qual Mitchell explica sua concepção de turn, substituindo o termo pelo título da coletânea na qual o artigo foi republicado em 1994. O autor corrigiu esse erro e retomou a expressão pictorial turn na segunda edição do livro, de 2009, a qual está sensivelmente modificada (Mirzoeff, 2009, p. 5).

125. Em Come vedere il mondo, texto-proposta mais recente de Mirzoeff (2018), a ubiquidade das imagens a partir da revolução infográfica constitui as viradas da experiência social visualmente dominantes no século XXI como experiência planetária - na avaliação distópica do autor - da possível extinção da raça humana.

126. Jay (2003-2004).

127. Jay retomou o volume de Foster (1988) para escrever sua versão da história da virada visual que, de fato, apresentou nos EUA múltiplos começos. A fortuna crítica da coletânea de Foster e dos estudos de Jay não pode ser subestimada, uma vez que gerou vasta bibliografia no meio anglo-saxão. Deve-se lembrar que a recepção dos trabalhos de Mitchell nos EUA foi marcada também por hostilidade de alguns interlocutores, como o próprio autor registrou em carta a Boehm: "A questão, que ainda parece um pouco 'bizarra', embora esteja convencido de sua relevância e necessidade, contribuiu decisivamente para criar um efeito de isolamento e ainda me lembro de alguns dos primeiros leitores, na revista de October, como Hal Foster, que me disseram que se tratava da questão errada - enquanto Annette Michelson fora muito mais tranquilizadora. Só recentemente alguns 
espíritos gentis me disseram que talvez, afinal, tenha encontrado algo de bom" (Mitchell, 2012, p. 138).

128. Dikovitskaya (2005).

129. Bredekamp (2003).

130. Mitchell (2005). A primeira parte do texto fora apresentada em 2000, e a segunda concebida para Hans Belting e Peter Weibel para o simpósio "Iconoclash Zentrum für Kultur und Medien" em Karlsrube, Alemanha, no verão de 2002.

131. Belting (2005). Existe tradução para o português desta segunda versão (Belting, 2006).

132. Belting (2005, p. 319).

133. Mitchell (2012). O artigo "Four fundamentals concepts of visual culture" parafraseava o título do seminário de Lacan Os quatro conceitos fundamentais da psicanálise. Este texto, porém, foi publicado apenas em 2008, posterior ao encontro entre Mitchell e Boehm em um seminário organizado por Hans Belting em 2005. Cf. Mitchell (2015c).

134. Moxey (2008). Isso torna os textos de Knauss (2008) e Moxey plenamente contemporâneos na aproximação das duas tradições. Cf. última seção deste artigo.

135. Moxey (2013a, 2013b). É interessante notar aqui a ausência de discussão da obra de Didi-Huberman nos trabalhos de Mitchell e Boehm, mencionado uma ou outra vez, algo que se destaca se pensarmos a importância daquele autor nos meios intelectuais francês e brasileiro (este último francófilo). Obviamente existem campos independentes de
Keith Moxey teceu a primeira consideração de destaque dos estudos alemães nos EUA e comparou as diferentes tradições dos estudos visuais e da ciência das imagens. ${ }^{134}$ Ele diferenciou o que chamou de modo anglo-americano de pensar as imagens como produtos culturais repletos de significados que precisam ser decifrados, representado por expoentes como Mitchell, Bryson, James Elkins etc., enquanto as perspectivas britânica, francesa e principalmente alemã - representadas por DidiHuberman, Boehm e Belting -veriam as imagens como presenças-agentes que provocam respostas em seus vedores. $\bigcirc$ uso da expressão iconic turn mostra a opção de Moxey, ao destacar a abordagem de Boehm, por debater a presença e a temporalidade das imagens, aproximando a reflexão da Bildwissenschaft alemã e a teoria da imagem francesa que tem em Didi-Huberman seu maior protagonista. ${ }^{135} \mathrm{~A}$ perspectiva de Boehm em especial concretizaria, como já dito, uma atitude dêitica para com as imagens, as quais ofereceriam algo mais do que a significação linguística. Ou seja, a leitura de Moxey concebe a (não) hermenêutica da imagem de Boehm em uma chave pósfenomenológica. A ideia de "presença" na avaliação de Moxey é central, uma vez que todos os novos paradigmas sobre a participação das imagens na configuração do mundo humano remeteriam, segundo o autor, a considerálas como formas que estão além do horizonte da significação ou do método hermenêutico.

A divisão de Moxey apresenta certa generalização. Foi como crítica ao paradigma hermenêutico que o princípio analítico e descritivo-plástico lou gramática) ${ }^{136}$ de Mitchell desenvolveu uma abordagem interessada numa história do funcionamento das imagens ${ }^{137}$ no qual "sentido", "uso" e "presença" estariam em jogo entre imagem e texto. Mais do que interpretar, para Mitchell trata-se de torcer os campos sociais de usos e interpretação que se confrontam. Pode-se chamar isso de uma dialética fraturada entre palavra e imagem, o que significa uma posição no mínimo transversal em relação à esmagadora maioria das modalidades de hermenêutica. A noção de agência das imagens ${ }^{138}$ é comum aos modos estadunidense, francês ou alemão, e sem dúvida a virada icônica alemã realça a força própria das imagens de encadear eventos e dispor novas formas, relações e cognições. Neste sentido, as imagens geram conhecimento - na linguagem e fora dela -, e a virada icônica de Boehm permite entrever outro movimento da linguagem em seu funcionamento descritivo e analítico sobre suportes e materiais cuja presença físico-plástica imagética é tão importante quanto a significação e os paradigmas a ela associados. Contudo, como mostramos, não se pode subestimar a matriz hermenêutica na formulação das ideias de Boehm, para quem o "decifrar" a imagem por meio da linguagem continua sendo um problema central.

Seria por iniciativa alemã a aproximação mais profícua entre a pictorial turn e a iconic turn, encaminhada por Belting, que deu uma nova sobrevida à "virada" 
no seminário organizado entre 21 e 23 de abril de 2005, com o título Bildwissenschaft? Eine Zwischenbilanz ("Ciência da imagem, um balanço provisório"). $\bigcirc$ evento contou com a apresentação atualizada de What do pictures want?, 139 de Mitchell, na abertura, e teve Das paradigma "Bild" como encerramento de Boehm. ${ }^{140}$ Em 2007 esses autores trocaram duas cartas, a primeira endereçada por Boehm a Mitchell, The iconic turn: ein brief, seguida pela resposta de Mitchell, Pictorial turn: eine antwort, ambas publicadas no volume organizado por Belting, Bilderfragen: die Bildwissenschaften im Aufbruch (Questões de imagem: a ciência da imagem em movimento). ${ }^{141}$ Essa fortuna crítica permanece testemunho, programa e reinvenção do passado recente dos estudos visuais e da ciência da imagem, bem como uma tentativa de colocar a metáfora absoluta da virada pictórica/icônica em perspectiva. ${ }^{142}$ Abrindo mão do discurso do pioneirismo, Mitchell e Boehm se assumem, contudo, catalizadores dos debates em seus contextos acadêmicos: o segundo afirma que sua proposta de virada icônica era uma reação e ampliação da virada linguística e jamais teve por fim eliminá-la, mas lançar a discussão ao redor de outros princípios cognitivos que correm paralelos à linguagem. Estabelecendo uma distinção importante, Boehm afirma que a iconic turn propunha-se como uma mudança de "paradigma" (no sentido de Kuhn), sendo, portanto, distinta da noção de "tropo" que estava na base da explanação de Mitchell em sua pictorial turn. Boehm concebia seu trabalho na diferenciação que as imagens produzem como pedra de toque. $\bigcirc$ iconic da expressão não remeteria a Pierce (como em Mitchell), mas a outra tradição e serviria para marcar a "alteridade das imagens":

○ "icônico" não se subtrai da linguagem, mas se diferencia desta. Próprio como o olho, assim também a imagem não é inocente ou imediała, mas é variamente correlacionada aos contextos de pensamento, gênero, sexo, cultura, ideologia e discurso nos quais vê a luz. $\bigcirc$ que não significa, obviamente, que possa ser deduzida destes contextos. A "minha" é então uma virada de crítica da imagem, não de crítica da ideologia. ${ }^{143}$

Boehm tinha por fim produzir uma compreensão diferenciada da "lógica das imagens". Ao reconstruir sua própria trajetória, afirmou que a formulação da diferença icônica objetivava tratar das experiências advindas da presença icônica, ou seja, formas visuais irredutíveis aos textos - seria a própria imagem como evidência de um processo cognitivo irredutível ao discurso, mais adequada, portanto, à compreensão de experiências sociais com um horizonte de presença da imagem. ${ }^{144}$ A dêitica complexa das imagens realça o quanto elas saem da contenção dos discursos do passado (e do presente), como uma heurística da história das imagens nos diversos tempos históricos. debate nos EUA, na França e na Alemanha. Especulando, arriscamos encaminhar a discussão: (1) a matriz warburguiana, a pura visibilidade, a hermenêutica e a discussão da virada icônica constituíram matrizes diversas para Boehm, assim como a semiótica, a desconstrução à americana, Northrop Fry e os estudos culturais para Mitchell. (2) O essencial das formulações de Boehm e Mitchell é anterior à autorrevolução benjaminiana de DidiHuberman de Ce que nous voyons, ce qui nous regarde em 1992 (1998), a partir da qual o filósofo/historiador francês parece conquistar o protagonismo na academia francesa. (3) O papel da iconoclastia em Boehm e Mitchell foi diverso daquele para Didi-Huberman: diferente deste último, aqueles não estavam interessados em redefinir campos acadêmicos pelo exorcismo dos mestres/ ícones do passado. A iconoclastia para os três é um objeto, mas apenas para Didi-Huberman foi componente central da prática teórica no interior da disciplina, como se pode depreender de sua reescrita da história da arte desde Devant l'image (1990), seguindo por Devant le temps, de 2000 (Diante do tempo, 2016), L'image survivante (2002) $\mathrm{e}$ Survivance des lucioles, de 2009 (Sobrevivência dos vaga-lumes, 2011). Talvez a reflexão de Jay sobre escopofilia e difamação da visão na filosofia francesa ajudasse a compreender as obras de Didi-Huberman - e também a de Mitchell e Boehm. É evidente que tudo aponta à originalidade dos três autores.

136. Cometa (2018, p. 2026) aborda a gramática das imagens de Mitchell, reconhecendo que o próprio 
Mitchell contestaria essa afirmação.

137. Cf. Alloa (2012); Meneses (2004; 2012).

138. Sobre agência das imagens e artefatos Cf. Gell (1998).

139. A primeira versão resumida do texto foi publicada em October (1996), como What do pictures really want?. Apareceria novamente no livro What do pictures want, coletânea de artigos de Mitchell lançada em 2005.

140. O programa está disponível em: <https://bit. 1y/2VV71TJ>. Outros importantes pensadores alemães estavam no evento, como Peter Geimer, Belting e Horst Wenzel.

141. Belting (2007). Esses textos foram traduzidos para o inglês no volume organizado por Neal Curtis em 2010, The pictorial turn, cujo título retomou a expressão de Mitchell. A diferença das coletâneas alemã e inglesa é abissal. A primeira, além das cartas mencionadas e dos textos de Geimer, Belting, Klaus Krüger, Wenzel, Jean-Luc Nancy, entre outros, propõe uma avaliação do ponto de vista da tradição germânica. As mesmas cartas, na versão inglesa, são seguidas pelas contribuições de Rancière, Jay, Morris, Morss, Mirzoeff, Stephen Daniels e outros, conduzindo o problema para o campo dos visual studies e da visuality. Curiosamente o termo visual turn aparece pouco na coletânea inglesa e não parece relevante na proposta alemã. Na versão inglesa constam alguns dos textos presentes em outra coletânea, Pensee l'image (Alloa, 2015). A introdução de Curtis ao volume está mais interessada em debater a ideia de vida das imagens de Mitchell e toma como
A resposta de Mitchell avaliou o projeto conceitual da pictorial turn, afirmando que um paradigma podia ser também um tropo:

Coerentemente, então, eu propus que a virada pictórica seja como uma mudança de paradigma no âmbito das atuais disciplinas acadêmicas (com um renovado interesse pelas representações não verbais, segundo aquelas correntes filosóficas e linguísticas que você [Boehm] documentou), seja do ponto de vista do que eu chamo de um "tropo recorrente", que se determina quando um novo repertório de imagens, ou uma nova tecnologia para produção de imagens, criam uma ansiedade difusa, um tipo de "pânico icônico" somente acompanhado por expressões de temor e gestos iconoclastas. Como eu escrevi em Picture theory, uma virada pictórica envolve tanto "as disciplinas das ciências humanas quanto [...] a esfera da cultura pública". Por esta razão sustentei que "viradas icônicas" ocorreram também no passado, e comportaram algum tipo de confronto entre a cultura intelectual e a esfera pública, desde a reflexão de Platão e Aristóteles sobre artes da imagem sobre a opsis até a invenção da pintura a óleo e da perspectiva, ou aquela da fotografia. Sustentei também que uma virada icônica não depende necessariamente de uma nova tecnologia, mas é um produto de um movimento social delimitado pelo medo de uma nova imagem. A volta icônica, no meu modo de ver, é sempre frequentemente avistada, em primeiro lugar, pelos iconoclastas, que denunciam com alarme e horror o advento de uma "imagem do mundo" maligna. ${ }^{145}$

Esta consideração de Mitchell tem duas implicações importantes: primeiro acentua a proposta original de Picture theory, ao transformar o que chamava de "tropo" numa descrição/interpretação histórico-iconológica de diversos momentos culturais; segundo, transforma definitivamente a virada icônica ${ }^{146}$ numa consequência das ansiedades sociais para com as imagens, não sendo necessariamente marcada por precedentes acadêmicos ou ligada a um dado salto tecnológico, mas a novas emergências pictóricas-ideológicas.

A virada estaria, portanto, ligada à composição de tropos/paradigmas de enfrentamento da ansiedade visual. Isso significa que: (a) cultura visual existe em toda sociedade que produz imagens; (b) uma virada visual emerge em um contexto histórico no qual novas imagens (ou velhas imagens retomadas) desafiam algum padrão vigente. A virada visual da modernidade industrial, portanto, tem peculiaridades históricas relacionadas às novas tecnologias, contudo, formas plásticas que catalisam as forças sociais podem produzir viradas a partir de mídias e suportes já conhecidos. Neste ponto, Mitchell realça os contextos sociais de visão e visualidade nos quais se produzem viradas que se confundem com a emergência de rompantes de imagens. Se a filosofia e as ciências ocidentais produziram reflexões sobre as imagens, isso é uma parte do fenômeno e não o definidor da própria virada.

Em realidade, Mitchell e Boehm parecem entender suas "viradas" como sinônimos, ainda que com realces diferentes. Ao contrário da concepção de Mirzoeff, 
a "virada" não estaria relacionada ao mundo acadêmico, mas aos variados tratamentos culturais (pictóricos, discursivos e práticos) dados às imagens. Para ambos, a virada seria anterior a sua sistematização disciplinar nos anos 1990. Segundo Boehm, o modernismo de certa forma fez a virada antes da filosofia, mas fora nesta - e na história da arte - que uma nova epistemologia começou a se consolidar. ${ }^{147}$ Para Mitchell, a "verdadeira" mudança estaria na relação pública com a produção de imagens, na reação às imagens existentes, bem como os discursos e tropos de reação e produção das imagens estariam no centro do problema. Isso significaria que a virada visual é uma tomada de consciência prática da sociedade sobre a produção de imagens. A teoria contemporânea e os estudos visuais seriam apenas a "face disciplinar" dessas reações.

Na França, Alloa organizou um debate de alcance internacional, com a colaboração de Boehm, Mitchell, Didi-Huberman, Rancière, entre outros, no seminário Penser l'image apresentado no Collège Internacional de Philosophie, em 2007 e 2008. Mais tarde os resultados seriam publicados como livro, com textos importantes de Boehm e Mitchell combinados com uma série de reflexões sobre problemas da iconoclastia (Marie-Jose Mondzain), mimesis Uean-Luc Nancy) e simulação (Emanuele Coccia) e a relação imagem-cognição (Belting, Bredekamp). ${ }^{148}$ A proposta de Alloa atrela a reflexão sobre "iconicidade" à transparência e opacidade, tópico ao qual o autor retornaria com maior refinamento anos depois, radicalizando a discussão de Mitchell e Boehm a partir da sintomatologia de DidiHuberman. ${ }^{149}$ Alloa considera que a virada icônica configura uma "arqueologia" (busca dos traços deixada pelas imagens na filosofia e, estendemos, no convívio social), uma "poética" (compreensão do que significa ver por meio de imagens) e uma "episteme" loutra forma de conhecer ou, no vocabulário do próprio autor, "aprender a desconhecer"). ${ }^{150}$ De fato, Alloa evidencia um deslocamento sobre o pensar a imagem que transporta diretamente ao horizonte acadêmico francês da théorie de l'image, como chamaram Antonio Pinotti e Andrea Somaini. ${ }^{151}$

Depois destes debates, emergiram avisos sobre os abusos acadêmicos realizados em nome da virada visual, 152 bem como diagnosticou-se a expansão de seu horizonte na busca de viradas icônicas no cinema ${ }^{153}$ e de uma iconic turn na sociologia da vida social da cultura material, uma espécie de sociologia cultural a partir da iconicidade. ${ }^{154}$

Na Itália, as viradas pictórica e icônica foram entendidas como duas formas de trabalho sobre temas comuns, criando um propício campo de diálogo. A partir dos estudos de literatura e arte, filósofos, historiadores da literatura e da arte mobilizaram diferentes abordagens que conectaram as perspectivas de Mitchell e Boehm. Cometa insistiu nas diferenças e aproximações entre essas naturalizada a pictorial turn. Perceba-se que a virada pictórica/icônica/visual atinge uma sinonímia sobre a qual nenhum debatedor deseja oferecer um veredicto.

142. Usamos a tradução italiana das cartas publicadas na revista Lebenswelt (2012), em que constam as contribuições de Alloa, Vargiu, Angelo Mengoni, Pietro Conte e Michele Di Monte. O debate italiano permite colocar em perspectiva o modo como a virada funciona em diversas comunidades acadêmicas. A Itália tem sido marcada pela forte interlocução com os alemães no campo da história da arte e da estética. Benedetto Croce, por exemplo, foi um dos propagadores da "pura visualidade" da língua alemã na Itália, inclusive da obra de Konrad Fiedler. Também se destaca a hermenêutica, principalmente o impacto de Gadamer (Dottori, 1981; Ruschi, 1986), em grande parte introduzido na Itália por Gianni Vattimo nos anos 1950. O trânsito entre historiadores da arte e estudiosos da literatura alemães, austríacos e italianos garantiu muitas trocas. A escola de Warburg é velha interlocutora de italianos (comumente sob crítica) como Eugenio Garin (que era amigo de Frances Yates), Giulio Argan e, mais recentemente, Salvatore Settis, entre tantos. A conhecida colaboração de Delio Cantimori com Yates, bem como seu acesso ao Instituto Warburg (IW) não pode ser subestimada, estando na base do estágio de Carlo Ginzburg no instituto, quando surgiu conhecido ensaio (Ginzburg, 2009). Yates também recebeu Agamben para trabalhar no IW, cuja marca se faz sentir nas primeiras obras do filósofo. Traduções de Fritz Saxl e Edgar Wind circulam na Itália desde os 
anos 1950 . A Bildwissenschaft faz-se sentir no meio italiano desde 1980, existindo traduções de Boehm (1981, 1986) que remontam a antes da fama dos visual studies. Também Belting e Bredekamp têm sido repetidamente traduzidos para o italiano desde os anos 1980. Já o debate com Mitchell remonta à apropriação dos estudos culturais na Itália ainda nos anos 1980, sendo feita uma coletânea de seus artigos em 2007. Em 2009 publicou-se uma coletânea com textos de Boehm. Essa lista seria estendida longamente, incorporando todos os estudiosos italianos que dialogam com essas tradições desde os anos 1990 (Michele Cometa, Andrea Pinotti, Antonio Somaini, Maria Monte, Tonino Griffero, Federico Vercellone, Maria Bettetini etc.).

143. Boehm (2012, tradução minha).

144. Vê-se o motivo pelo qual Moxey (2008) estabelece afinidades entre Didi-Huberman, Boehm e Belting como uma epistemologia da presença próxima das ideias de Hans Ulrich Gumbrecht. Ironicamente Belting pensa o seu próprio trabalho como uma iconologia, mais próximo de Mitchell.

145. Mitchell (2012, p. 134 , tradução minha)

146. O autor usa as expressões inglesa e alemã no decorrer do texto. Quando usa picturial turn é para marcar sua forma de conceber o debate pela primeira vez, ao passo que o termo alemão traduzido (icônica) estabelece a identificação com o projeto intelectual de Boehm e da ciência das imagens.

147. A mesma tese de abordagens para gerar uma renovação nos estudos de objetos culturais. ${ }^{155}$ Michele di Monte e Maria di Monte têm divulgado longamente o tratamento da svolta iconica de Boehm como base de trabalho de pesquisa sobre literatura, arte e filosofia contemporânea, no que têm sido prontamente acompanhados por Tonino Griffero. ${ }^{156}$ Já Pinotti e Somaini deram sua própria versão do encontro das viradas. ${ }^{157}$ Aproximando os visual culture studies, a Bildwissenschat e a théorie de l'image francesa, postularam uma virada visual transdisciplinar para a qual: (1) como elaboração prático-teórica, a consciência do poder das imagens e a ansiedade por elas produzidas abriram um movimento intelectual de diagnóstico das viradas pictórica/icônica, advindo da vivência na iconosfera ${ }^{158}$ do século XX; (2) o ponto de partida é que todas as imagens e experiências visuais podem ser tratadas como parte do tecido de suas culturas, objetos e atos sociais historicamente determinados. Neste âmbito, existe uma irredutibilidade e uma lógica próprias da imagem para além da linguagem e que demanda uma heurística da iconicidade. Os autores postulam que a superação do primado da virada linguística advém do fato de que o pictórico e o icônico são imagensartefatos, concebendo-os como "sujeitos e quase-pessoas animadas". ${ }^{159}$ Malgrado a imensa diferença, Boehm e Mitchell são aproximados como promotores do deslocamento intelectual de uma virada que teve um "duplo batismo". 160

Pinotti e Somaini organizaram uma coletânea ${ }^{161}$ para apresentar ao público italiano alguns dos textos antológicos e eixos de trabalho da área, contemplando as matrizes alemã, estadunidense, holandesa, francesa e italiana. Anos depois escreveram ampla apresentação dos aspectos teóricos e campos de trabalho sobre cultura visual, definindo a abertura produzida pela "virada pictórica/icônica" lassim chamada por eles). ${ }^{162} \mathrm{~A}$ novidade de sua abordagem é apontar o horizonte de relação entre os novos estudos e uma virada pictórica/icônica que é consciente de sua multiplicidade acadêmica e produz diálogos com disciplinas inesperadas, como a neurociência, tratando das perspectivas estéticas e biológicas sobre o humano como sujeito coletivo e biológico. ${ }^{163}$

Segundo estes mesmos autores, recorrendo à ampla bibliografia alemã, a iconic turn se configura também como uma medial turn que se interroga sobre "as diversas formas de mediação técnico-material em todas as formas de experiência e de consciência". ${ }^{164}$ A medial turn é uma proposta multissensorial para constituição da realidade sócio-histórica que está no horizonte imediato das possibilidades da virada visual, cujos estudos dão especial atenção à técnica, à tecnologia, aos corpos e aos suportes materiais ${ }^{165}$ que condicionam as presenças das imagens e as práticas de significação possível, ou seja, apontam às mediações técnicomateriais de toda forma de experiência e conhecimento. ${ }^{160}$ Em especial, essas 
interfaces valorizam, para além da presença e significação da imagem, a "performatividade bio-ambiental" bem como a construção da emocionalidade socialmente partilhada. ${ }^{167}$ A virada pictórica/icônica/visual continua sua fortuna crítica como mudança ou prenúncio de mudanças, uma metáfora absoluta epocal.

Também na Espanha e em Portugal ocorreu uma virada visual dos estudos da imagem por meio de projetos, seminários, traduções e intercâmbios. Sob comando de José Luis Brea, Luis Vives-Ferrándiz Sánchez e Miguel Angel Hernández Navarro, na Espanha - o primeiro a frente de publicações na editora Akal ${ }^{168}$ e os dois últimos atuando no Centro de Estudios de la Imagen Sans Soleil (CEISS) ${ }^{169}$-, ocorre forte diálogo com as vertentes anglo-americanas, que tem tido ampla penetração na América Latina. Em Portugal, por sua vez, o projeto Ymago ${ }^{170}$ tem sido uma fonte interdisciplinar de divulgação de perspectivas, notadamente de matrizes francesa e alemã. As traduções lusitanas têm sido uma fonte alternativa para a leitura, em português, de perspectivas diversas.

\section{A IMAGEM/ARTEFATO QUE NOS IMAGINA JUNTO A NÓS}

Queimar a bruxa-Butler é criar um artefato que serve para canalizar certa representação, enviar uma mensagem, mas também fazer viver certa ansiedade. Isso só é possível pela alteridade material e plástica do artefato: a boneca não era, mas era Butler, reconstruída a partir de certo feminino que deveria ser negado la bruxa), como sempre foram as bruxas assassinadas no decorrer da história. Como não se pode queimar a mulher real, queima-se a mulher-imagem, num exorcismo mágico-político coletivo. Aqui surpreendemos a construção social de um corpoimagem que só foi possível porque seus usuários praticaram certa alteridade icônica, produziram um ícone.

Revela-se o aspecto público da virada pictórica/icônica/visual, a qual possui outras dimensões que articulam essa alteridade. A virada à imagem apresenta uma potência heurística de indagar os fenômenos da vida pública e, mais do que uma moda acadêmica, permite perceber como as pessoas cotidianamente mobilizam imagens, fazendo-as existir e/ou viver. Reconhece-se uma alteridade que a abertura heurística da virada icônica permite articular. Como metáfora absoluta das humanidades, a virada pictórica constitui um catalizador das vivências sociais.

A virada visual só tem utilidade numa realidade acadêmica como a brasileira se permitir uma articulação a partir das condições de vida locais e de sua posição na relação centro-periferia. ${ }^{171} \bigcirc$ que seria, por exemplo, uma
Bredekamp (2003) sobre a origem da Bildwissenschat.

148. Volume traduzido no Brasil como Pensar a imagem (Alloa, 2015).

149. Alloa (2012, p. 146) considera que a pergunta fundamental de Mitchell continua sendo válida: "a imagem constitui em suma, no interior das ciências humanas, uma anomalia ou um paradigma?". O filósofo retoma a consideração de Mitchell e o valor do icônico em Boehm (2009b) para postular que a iconicidade não é uma diferença entre entes (coisas) e signos ou uma subcategoria semiótica.

150. Alloa (2012, p. 150).

151. O debate francês está além do escopo deste ensaio. Aparentemente a virada visual, no meio francês, não foi nomeada diretamente na reflexão sobre imagens, ainda que se perceba um funcionamento da metáfora absoluta da "virada", principalmente a partir dos anos 1990. A reflexão francesa sobre imagem é gigantesca e espalhada por disciplinas diversas: os estudos fílmicos; a fenomenologia; a psicanálise; a semiótica; filosofia, história da arte, articulando inúmeras concepções - a imagem como matéria-prima ou opacidade; a teoria dos dispositivos; a tradição da escopofilia e da iconoclastia. Destaque-se uma théorie de l'image nas obras singulares de Jean-Jacques Wunenburger, Daniel Arasse, Philippe Dubois e Didi-Huberman, incluindo ainda reflexões de Rancière e Nancy. Cf. Huchet (2012); Pinotti; Somaini (2009; 2016); Wunenburger (1999).

152. Hentschel (2014).

153. Berezhnaya; Schmitt (2013). 
154. Alexander; Bartmanski (2013).

155. Cometa (2004; 2012; 2017), Cammarata (2017).

156. Griffero (2009); Monte; Monte (2009).

157. Pinotti; Somaini (2009; 2016).

158. Iconosfera: "A esfera constituída pelo todo das imagens que circulam em um determinado contexto cultural, pelas tecnologias com as quais elas foram produzidas, elaboradas, transmitidas e arquivadas e pelos usos sociais dos quais essas mesmas imagens são objetos" (Id., 2016, p. 18).

159. Id., 2009, p. 15

160. Monte; Monte (2009, p. 9).

161. Pinotti, Somaini (2009).

162. Id., 2016. Talvez seja a resenha mais ampla já publicada sobre o assunto.

163. Tem sido um dos investimentos de Pinotti produzir diálogos entre tantas disciplinas quanto possível para evidenciar a força das imagens e da estética na constituição do ser humano, da consciência e da coletividade. Destaca-se o diálogo com a neurociência, em parte incentivado pela descoberta dos neurônios-espelhos conceito biológico que usa outra metáfora absoluta, a do espelho - nos meios científicos italianos, a qual suscitou inúmeros diálogos interdisciplinares na península itálica. Cf. Freedberg; Gallese (2009); Pinotti; Lucignani (2009); Pinotti; Tedesco (2013).

164. Pinotti; Somaini (2016, p. 28).

165. As interfaces disciplinares com a cultura material se destacam a partir virada pictórica no Brasil, tanto como fenômeno da esfera pública como da produção acadêmica, para além da aparente apropriação de ideias estrangeiras? Em que medida "abrasileiramos" a virada? ${ }^{172} \mathrm{Ou}$, dizendo mais acertadamente, como ela é aqui vivida/pensada?

Como já mencionado, as primeiras sistematizações no Brasil dos estudos de cultura visual e da virada visual ocorreram nas publicações de Ulpiano Meneses e Paulo Knauss, ambas posteriores à avaliação, em 2002, de Jay, ${ }^{173}$ a qual é incorporada por ambos. ${ }^{174}$ Meneses produziu seu próprio diagnóstico, evidenciando as possibilidades de pensar o visual, o visível e a visão como campos principais de atuação da nova epistemologia, escapando da hipertrofia teórica e assegurando que se tratava de entender a alteridade por meio da qual a imagem funcionava no social. Em sua abordagem sentia-se o peso dos estudos de cultura material, preocupado com a materialidade das imagens, aproximando-se de conceitos e propostas historicamente documentadas e que ressaltem a circulação de artefatos e suas trajetórias, aspectos que o autor realçaria em textos posteriores. ${ }^{175}$

Knauss, por sua vez, realizou uma leitura atenta da trajetória de formação dos conceitos e evidenciou o "desafio" de fazer historiografia com as imagens. ${ }^{176}$ Anos depois, ${ }^{177}$ iria além ao introduzir a discussão mais ampla sobre os visual studies e a Bildwissenschaft, e, incorporando as propostas recém introduzidas pelos artigos de Bredekamp, Belting e pelo livro de Dikovitskaya nos EUA, 178 tratava a noção de que "a imagem aparece como problema" multidisciplinar e que sua "dimensão intelectual de fundo" evidenciava que ela não era um dado, mas "uma construção". ${ }^{179} \mathrm{~A}$ tradição de pesquisas historiográficas brasileiras sobre imagens se apropriou da virada visual, mediada justamente por uma preocupação com sua faceta histórica, evitando discussões teóricas hipertróficas e focando nas orientações possíveis de trabalho com história das imagens. Foi na historiografia e na história da arte e da fotografia, em diálogo com os estudos de museologia, arqueologia, acervos, patrimônio e simbologias, ${ }^{180}$ e, em alguma medida, nos estudos de comunicação, que se realizou no Brasil a apropriação dos visual studies e da virada visual, o que encadeou certa forma de discussão sobre seus pressupostos.

Destaque-se, como afirmam Schiavinatto e Costa, ${ }^{181}$ a criação do Grupo de Trabalho da Associação Nacional de História (ANPUH), Cultura Visual, História e Imagem, fundado em 2005 e refundado em 2011, importante iniciativa que integra pesquisadores de todo o Brasil. Seminários têm sido cada vez mais comuns, iniciados em 2008, com "Crise da imagem ou crise da teoria", seminário organizado por Jens Baumgarten, do Goeth Institut, que contou com a presença de Belting; em 2010 ocorreu o I Congresso Internacional Texto-Imagem, organizado por Leila Aguiar e Osvaldo Fontes Filho, ${ }^{182}$ e os dois 
eventos do GT ANPUH, os seminários internacionais "Cultura visual e história", com a primeira versão em 2012,183 organizado na Pontifícia Universidade Católica do Rio Grande do Sul (PUC-RS) por Charles Monteiro, e em 2014184 na Unicamp, com lara Schiavinatto na organização.

Uma das características da apropriação da virada visual no Brasil, como já apontamos, parece ser uma abordagem que valoriza a produção, circulação e os funcionamentos das imagens, tal como diagnosticado por Meneses, Knauss e Costa e Schiavinatto. ${ }^{185}$ A valorização da iconicidade como parte da relação entre visível e invisível, materialidade e imaterialidade é uma potencialidade local e um traço específico da virada visual em terras tropicais. ${ }^{186}$ Como hipótese sugerimos que entre nós teríamos a convivência de abordagens diversas, que enfocam (a) práticas de significação e semânticas históricas das imagens e/ou (b) usos da iconicidade na cultura material, em um sentido amplo desta expressão. A comunidade brasileira, especificamente, parece refratária às dúvidas ontológicas típicas de meios acadêmicos como o alemão e o francês. ${ }^{187}$

Haveria, contudo, áreas ou domínios reorganizados pela virada à imagem, seja no Brasil e/ou no além mares, rios e florestas? Do complexo cenário aberto por Mitchell e Boehm tiramos o que consideramos alguns núcleos da epistemologia/alteridade da imagem: vidas; corpos; usos; cognição e afetos; intersubjetividade. Estes atravessam aquilo que Meneses chamou de "visível" (sistemas de controle do ver/ser visto), "visual" (imagens e seus sistemas de circulação) e "visão" (tecnologias e dispositivos de observação e olhar) ${ }^{188}$ e contemplam a listagem de Costa e Schiavinatto:

A imagem ontologicamente tramada através de processos históricos se define em meio a um complexo jogo entre visualidades, dispositivos, instituições, tecnologias, discursos, figurações, materialidades, poderes, desejos, linguagens, processos de significação coletivos partilhados e entremeados a processos de subjetivação, operações de memória-esquecimento, erigindo-se, assim, num artefato cultural, mesmo quando a imagem, que muitas vezes busca a linguagem, torna-se invisível, desaparece, ou não chega a constituir sentido. ${ }^{189}$

Quanto ao primeiro núcleo, "vida" das imagens nos diversos tempos e espaços, historiadores na Grécia antiga, ${ }^{190}$ na Europa ocidental, ${ }^{191}$ na América ameríndia, ${ }^{192}$ no Congo da era moderna ${ }^{193}$ e na atualidade ${ }^{194}$ mostram que existem imagens que ofendem e são ofendidas, choram e fazem chorar, sangram e fazem sangrar, convocam ou são convocadas, abençoam ou amaldiçoam com suas presenças físicas ou imateriais. Mesmo as figuras que se sabe "mortas" são vivificadas para serem destruídas, como ocorre nas ondas iconoclastas de aportes da arqueologia, museologia, antropologia, história da arte para citar apenas algumas disciplinas. Basta observar o trabalho fundamental de David Freedberg (1989). Não por acaso Marcelo Rede afirmou que, sucedendo ao aporte culturalista e linguístico de d e s m a teria 1 i z a çã o encarnado na linguistic turn, adviria uma material turn (Rede, 2012, p. 144).

166. Proposta multifacetada desenvolvida com este termo na Alemanha nos trabalhos de M. Rimmele, K. Sack-Hombach, D. Mersch, J. Schorter (Pinotti; Somaini, 2016). Nos EUA, essa tem sido uma das propostas de Claire Farago (2016). No Brasil, Jens Baumgarten (2016) chamou atenção a esse aspecto. Seja material turn ou medial turn, a virada enquanto metáfora absoluta fica evidente como articulação de possibilidades acadêmicas e cognitivas.

167. Freedberg; Gallese (2009); Griffero (2009).

168. Destaque-se a pioneira coletânea organizada por Brea (2005), com introdução apresentando os visual studies, além de textos de inúmeros estudiosos dos EUA e Espanha.

169. Projeto editorial do CEISS disponível em: $<$ https://bit.ly/2DaUjdj>.

170. O Ymago é um "Projecto de difusão de autores que pensam a imagem em termos inovadores, explorando com grande liberdade e pertinência o seu enraizamento $\mathrm{e}$ as suas relações com as mais diversas problemáticas, saberes, crenças e práticas". Disponível em: <https://bit. ly/2DaNGYu>. Também a editora Dafne tem apresentado traduções para o português de obras de Belting e Didi-Huberman. 
171. Existem condições que tornaram possível o debate sobre a virada visual, seu alcance e sua "chegada" em outros ambientes intelectuais como o Brasil. Ela emergiu em grandes universidades, como a de Chicago, de Basel, de Heidelberg, de HumboldtBerlin e de Berkeley. Estes espaços sociais partilham de um lugar de poder epistêmico central, certa correspondência a duas potências: EUA e Alemanha. O lugar epistêmico da virada visual é, com isso - ainda que intrinsicamente crítico de sua própria posição -, ligado a uma perpetuação da sistemática centroperiferia capitalista, marcada por alto valor da produção euro-americana; uso do idioma do império (inglês); repetições um certo número limitado de autores e temática ao redor do globo. Cf. Pereira (2018).

172. Poderíamos citar também a instigante reflexão de Baitello Júnior (2014) sobre iconofagia.

173. Jay (2003-2004).

174. Knauss (2006); Meneses (2004).

175. Id., 2012.

176. Knauss (2006).

177. Id., 2008

178. Belting (2005); Bredekamp (2003); Dikovitskaya (2005).

179. Knauss (2008, p. 165).

180. Como ocorreu em outros países, no Brasil foi no desdobramento das pesquisas com material visual que novas formas de problematizar a imagem pela historiografia foram constituídas. Tratava-se de responder dúvidas sobre conjunturas históricas nas quais as imagens ocupavam um papel de destaque, revolucionárias ou revoltas de ontem ou hoje, ${ }^{195}$ indo desde ataques a terreiros afro-brasileiros à destruição das colossais estátuas de Budas de Bamiyan pelo Talibã, em 2001, e da cidade de Palmira pelo ISIS, em 2015. A vida das imagens resulta da oscilação entre estados de agência e sujeição que as pessoas experimentam com elas, definida por Mitchell como um desejo próprio de interagir. Elas devem ser consideradas "na ficção constitutiva das imagens como seres 'animados', quase agentes, pseudo-pessoas". 196 Também Bredekamp sugere que uma imagem deve ser pensada como algo similar a um ator social, no sentido de que analiticamente se pode "individuar a força" que the permite "saltar, mediante uma fruição táctil e visível, de um estado de latência à eficácia exterior no âmbito da percepção, do pensamento e do comportamento". ${ }^{197}$

Sobre os "corpos" das imagens, cabe destacar que, vivas ou não viventes, simulacros ou não, é nas diversas materialidades que as agências das imagens ocorrem como "presenças" sujeitas a usos. A "imagem material" e seus horizontes de "imaterialidade" são os aportes fundamentais. Suportes (fotografia, filme, infografia, pintura etc.), instituições (cinema, museu, arquivo, praça pública etc.) e artefatos (fitas, retratos, computadores, carros, quadros etc.) constituem formas sociais pelas quais as imagens se tornam acessíveis. A virada pictórica/icônica permite observar como a materialidade e a presença das imagens ${ }^{198}$ articulam modelos de experiência e temporalidades diversas para os sujeitos. A valorização da presença, que clama por uma atitude dêitica dos pesquisadores perante as imagens, é uma das possibilidades de encaminhar intelectualmente a iconicidade, ou seja, aquilo que como corpo-presença a imagem faz existir no mundo histórico. Ao problematizar a imagem, precisa-se atentar ao icônico como presença, ou, como chamou Boehm, à diferença icônica. As imagens demandam corpos e são movidas pelas pessoas, estas próprias, corpos (o primeiro "lugar das imagens") 199 que também se produzem como imagens quando se inscrevem pela mostração em alteridades sociais como raça, sexo, gênero, etnia etc. (como veremos a seguir). A condição existencial das imagens é dotada de sua própria antropologia, sua formação como corpos-significantes trata o icônico por meio de processos de significação e de seu "fazer-imagem", para tomar a feliz expressão de Belting. ${ }^{200}$

No tocante aos usos, como construção 201 as imagens resultam de "usos da cultura material", os quais são "práticas sociais" que conferem alteridade por meio da iconicidade em diversas dimensões sociais. As imagens poderiam ser concebidas como formas de vida porque são animadas pelas práticas sociais, pelas indexações sociais que se constituem como visuais ou que usam o visual para se constituírem. Elas funcionam como práticas sociais capazes de desenvolver dispositivos sociais de produção e circulação de imagens /como 
escolas, academias, universidades, museus, a emissão televisiva, a cultura fílmica, a imprensa etc.) ou formas fragmentadas de produção e consumo (usos privados de fotografias, pinturas, desenhos, softwares, corpos, objetos diversos), mais ou menos atreladas a dispositivos e instituições. ${ }^{202}$ Neste caso, os usos são integrações de performances, práticas discursivas e visuais, coadunando palavra, discurso, corpos e fazeres. Pode-se dizer que é nos usos da cultura material que surge o específico da abordagem heurística da virada à imagem: como dito, para além da pergunta "o que é uma imagem?", historicamente é muito útil pensar em "quando é uma imagem?". 203 Ou, perguntando com Sigrid Weigel, como o que não é imagem se transforma em imagem em dadas condições? Ou ainda, com Peter Geimer, quando imagens passam a ser evidências icônicas de outra coisa (o passado, por exemplo)?2204 A iconicidade, mais do que o próprio da imagem, é uma forma de perguntar sobre o mundo histórico, inclusive matrizes culturais diferentes.

Na "cognição" do mundo histórico, quarto núcleo analisado, destaca-se cada vez mais a forma como as imagens "fazem" compreender o mundo, geram conhecimento e saber (algo importante especialmente hoje, quando estão integradas em múltiplas tecnologias da informação e conhecimento). As histórias das imagens, da cultura material, da ciência e da produção e distribuição do conhecimento têm demonstrado o quanto as imagens foram fundamentais como tecnologias do conhecimento e na distribuição social do saber das sociedades do presente e passado. Trata-se de objeto de destaque nos últimos anos, a ponto de, nas cartas entre Boehm e Mitchell, ${ }^{205}$ a relação imagem e ciência ter sido um dos tópicos fundamentais do debate. Desenhar, pintar, cartografar, filmar, fotografar, decorar, exibir, construir, colecionar, expor, diagramar, musealizar, arquivar, etc. são atividades-fundamentos do modo de produção do saber e distribuição do conhecimento nas diversas sociedades, inclusive na própria organização das noções de presente, passado e futuro ${ }^{206}$ que usam diretamente as possibilidades icônicas na cognição. Indagar as maneiras de conhecer e desconhecer por meio de imagens permite compreender fenômenos do mundo histórico.

Resta abordar a "intersubjetividade" e o pathos dos sujeitos por/como imagens. A virada à imagem permite articular o papel desta na elaboração das trocas e afirmações de subjetividades, diferenças e identidades. A intersubjetividade já estava na base dos estudos feministas e na indagação sobre olhar e gênero, e foi reforçada com os estudos pós-coloniais, atingindo uma espécie de prioridade. A imagem faz ver outras alteridades que nela se espelham, se encarnam e por elas migram. A centralidade das imagens na designação de raça, gênero, sexo e outros padrões de pertencimento (nação, região, religião, localidade, grupos políticos, pesquisando sobre aquarelas, pinturas, gravuras (cf. Fabris, 1998; Lara, 2005; Lima, 2007; Schwarcz, 2008; Slenes, 1995), paisagens (Dias, 2009), celebrações e simbologias (Schiavinatto, 1999; Schwarcz, 1998), fotografias (Fabris, 1998; Kossoy, 2001; Mauad, 1997, 2008; Schwarcz, 1998; Monteiro, 2013), arte e patrimônio (Conduru, 2000; Knauss, 1998; Meneguello, 2008; Rubino, 2002) coleções, acervos e cultura material (Carvalho, 2008; Carvalho; Ferraz, 1997; Guimarães, 2007; Malta, 2011; Meneses; 1998; 2005) e cinema (Lucas, 2005; Santiago Júnior, 2009; Schvarzman, 2004).

181. Costa; Schiavinatto (2016).

182. Disponível em: $<$ https://bit.ly/2TM3uGw>

183. Disponível em: $<$ https://bit.ly/2AP142T>

184. Disponível em: <https://bit.ly/2ANWQsB>

185. Costa; Schiavinatto (2016); Knauss (2008); Meneses (2004).

186. Na produção deste texto foi muito útil a mediação do debate pela produção italiana, cuja originalidade ressalta sua condição centro-periferia (atualmente, quando a produção italiana tem grande circulação internacional, notadamente nos EUA, a Itália passa por uma periferização na geopolítica econômica europeia liderada pela Alemanha). Segundo Roberto Esposito (2010), as diversas tradições intelectuais italianas são marcadas, desde a Renascença, por um pensar a "relação política, vida e história", num esforço contínuo de tratar dos problemas da vida coletiva e de desenvolver sua 
reflexão afastada de uma filosofia do Estado e da Igreja, entrando no século XX afastada do "primado transcendental da linguagem" (a base da analítica inglesa, das filosofias francesa e alemã e das várias linguistic turns). Trazendo ao que nos interessa, estes aspectos conferem originalidade a um fórum de debate amplo com diversas tradições culturais. Sobre clássico e cultura italiana, cf. Settis (2004).

187. Apesar de haver no Brasil notável influência francesa, sentida hoje no impacto da tradução das obras de Didi-Huberman (que tem exercido grande renovação nas abordagens locais), os estudos de cultura visual brasileiros não parecem interessados na discussão filosófica das imagens em si mesma, como se observa numa rápida mirada de coletâneas (Costa; Schiavinatto, 2016; Flores, 2013; Monteiro, 2012) e dossiês publicados em revistas sobre cultura visual (Flores, 2010; Mauad; Lopes, 2014; Mauad; Monteiro, 2018; Souza, 2016).

188. Meneses (2004).

189. Costa; Schiavinatto (2016, p. 20).

190. Vernant (2001).

191. Belting (2001); Elkins (2003, 2009); Ginzburg (2001); Schmitt (2007).

192. Gruzinski (2006).

193. MacGaffey (2000).

194. Bettetini (2016); Ginzburg (2015).

195. A sociedade é marcada pelo iconoclash, os choques de ícones (segundo Latour, 2009); assim como as guerras de terror da a tualidade são profundamente iconofóbicas família, classe etc.) recondicionam as pesquisas sobre antigos e novos pertencimentos comunitários. Aqui a execração da boneca de bruxa com uma efígie da filósofa Judith Butler como um demônio da "ideologia de gênero" mostrase como uma operação misógina. A articulação da imagem com o poder e as formas sociais de distribuição de valores, de emprego da violência física e simbólica, bem como da construção de memória na esfera pública é também um dos tópicos fundamentais da virada às imagens. Tudo se combina com a noção de subjetividades integradas às intensidades das imagens, geradora de pathos que tende a acentuar ou negar os investimentos subjetivos que nelas são realizados.

Estas coordenadas apontam a "novidade" conceitual da alteridade das imagens. Se a "especificidade" destas nunca foi uma novidade em si mesma, os recursos interpretativos, até poucas décadas atrás, eram reféns das matrizes explicativas linguística e semiótica. A virada pictórica/icônica emergiu quando se concebeu que a imagem perturba os saberes tradicionais, os quais ajuda a constituir como uma heurística potencial. Compreender sua trajetória e suas consequências permite ver/saber como uma metáfora absoluta epocal, que abre o entendimento a partir do princípio da alteridade imaginal, funciona de forma inusitada, e talvez permita uma compreensão nova sobre episódios cotidianos e despercebidos de ontem e hoje, ou momentos sórdidos como queimar a boneca-Butler. 


\section{REFERÊNCIAS}

LIVROS, ARTIGOS E TESES

AGAMBEN, Giorgio. Stanze. Torino: Einaudi, 1977.

AGAMBEN, Giorgio. Infanzia e storia. Torino: Einaudi, 1978.

AGAMBEN, Giorgio. Aby Warburg e a ciência sem nome. In: AGAMBEN, Giorgio. A potência do pensamento: ensaios e conferências. São Paulo: Autêntica, 2015. p. 111-132.

ALBERA, François; TORTAJADA, Maria. Cinema beyond film: media epistemology in the modern era. Amsterdan: Amsterdam University Press, 2010.

ALEXANDER, Jeffrey; BARTMANSKI, Domink; GIESEN, Bernhard (orgs.). Iconic power: materiality and meaning in social life. New York: Palgrave Macmillian, 2013.

ALLOA, Emanuele. Iconic turn, alcune chiavi di svolta. Lebenswelt, Milano, n. 2, p. 144-159, 2012.

ALlOA, Emanuele (org.). Pensar a imagem. São Paulo: Autêntica, 2015.

ALPERS, Svetlana. Interpretation without representation, or, the viewing of Las Meninas. Representations, Califórnia, n. 1, p. 30-42, 1983.

ALPERS, Svetlana. A arte de descrever. São Paulo: Edusp, 1999.

ALPERS, Svetlana et al. Visual culture questionnaire. October, Cambridge, n. 77, p. 25-70, 1996.

BAITELlO JÚNIOR, Norval. A era da iconofagia. São Paulo: Paulus, 2014.

BALÁZS, Bela. Estetica del film. Roma: Edizione di Cultura Sociale, 1954.

BAUMGARTEN, Jens. Cultura visual e história da arte no âmbito da religião teorias e artefatos entre globalização e comparação. In: COSTA, Eduardo; SCHIAVINATTO, Iara Lis (orgs.). Cultura visual e história. São Paulo: Alameda, 2016. p. 123-143. (segundo Mitchell, 2011). Cf. Mondzain (2013).

196. Mitchell (2005, p. 46). No original "fiction as 'animated' beings, quasiagents, mock persons". Na versão brasileira, mock persons foi traduzido por um inadequado "simulacro de pessoas" (Mitchell, 2015b, p. 185). Mock designa não algo que ocupa o lugar de outro (o que seria próprio do simulacro), mas o fingir da imagem em ser o que é, ou seja, uma ficção de agente, uma subpessoa, um subalterno. O próprio autor esclarece que as imagens não são sujeitos plenos, mas "subalterns whose bodies are marked with stigmata of difference, and who function both as 'gobetweens' and scapegoats in the social field of human visuality" (p. 46). Também na tradução italiana a opção foi por pseudo-persona (Mitchell, 2009b, p. 118).

197. Bredekamp (2016, p. 36).

198. Boehm (2009b).

199. Belting (2013).

200. Ibid.; Mitchell (1996).

201. Knauss (2008)

202. Sobre dispositivos visuais e constituição social, cf. Albera; Tortajada (2010); Pinotti ; Somaini (2016, p. 172-192); Sandberg (1995).

203. Alloa (2012, p. 156)

204. Geimer (2015); Pinotti; Somaini (2016, p. 29-30); Weigel (2015).

205. Boehm (2012); Mitchell (2012).

206. Cf. Boehm (2009d); Bredekamp (2003; 2016); Guimarães (2007); Hentschel (2014); Mauad; Lopes (2014); Mitchell (2015a); Sandberg (1995). 
BAXANDALL, Michael. O olhar renascente: pintura e experiência social na Itália da Renascença. Rio de Janeiro: Paz e Terra, 1991.

BELTING, Hans (org.). Bilderfragen: die Bildwissenschaften im Auf. Munique: Verlag Wilhelm Fink, 2007.

BELTING, Hans. Il culto delle immagine: storia dell'icona dall età imperial al tardo medievo. Roma: Carocci, 2001.

BELTING, Hans. Image, medium, body: a new approach to iconology. Critical Inquiry, Chicago, v. 31, p. 302-319, 2005.

BELTING, Hans. Imagem, mídia e corpo: uma nova abordagem à iconologia. Ghrebh, São Paulo, n. 8, p. 32-60, 2006.

BELTING, Hans. Per una iconologia dello sguardo. In: COGLIOTORE, Roberto (org.). Cultura visuale: paradigmi a confronto. Palermo: Duepunti, 2008. p. 5-27.

BELTING, Hans. A verdadeira imagem: entre a fé e a suspeita das imagens: cenários históricos. Porto: Dafne, 2011.

BELTING, Hans. Antropologia delle immagini. Roma: Carocci, 2013.

BEREZHNAYA, Liliya; SCHMITT, Christian (orgs.). Iconic turns: nation and religion in Eastern European Cinema since 1989. Leida: Brill, 2013.

BETTETINI, Maria. Control le immagine: la radici dell'iconoclastia. Laterza: Roma-Bari, 2013.

BETTETINI, Maria. Distruggere il passato: l'iconoclastia dall'Islam all'Isis. Milano: Raffaelo, 2016.

BLUMENBERG, Hans. Paradigmi per una metaforologia. Milano: Raffaelo Cortina, 2018.

BOEHM, Gottfried. Immagine e tempo. In: DOTTORI, Riccardo; KUNKLER, Horst (orgs.). Estetica ed ermeneutica. Napoli: Pironti, 1981. p. 121-134.

BOEHM, Gottfried. Per una ermeneutica dell'immagine. In: RUSCHI, Ricardo (org.). Estetica tedesca oggi. Milano: Unicopli, 1986. p. 189-217. 
BOEHM, Gottfried (org.). Was ist ein Bild? Munique: W. FINK, 1994.

BOEHM, Gottfried. Il ritorno delle immagine. In: PINOTTI, Andrea; SOMAINI, Antonio (orgs.). Teorie dell'immagine: il dibattito contemporaneo. Milano: Raffaello Cortina, 2009a. p. 39-72.

BOEHM, Gottfried. La svolta iconica. Roma: Meltemi, $2009 \mathrm{~b}$.

BOEHM, Gottfried. Crescita nell'essere: riflessione ermeneutica e arte figurativa. In: La svolta iconica. Roma: Meltemi, 2009c. p. 145-166.

BOEHM, Gottfried. Mnemosine: la categoria del vedere rammemorante. In: BOEHM, Gottfried. La svolta iconica. Roma: Meltemi, 2009d. p. 245-276.

BOEHM, Gottfried. Iconic turn: una lettera. Lebenswelt, Milano, n. 2, p. 118-129, 2012.

BOEHM, Gottfried. Lo sguardo vivente: volto, ritratto, identità. In: MONTE, Maria Giuseppina di; MONTE, Michele di; RIEDMATTEN, Henri de (orgs.). L'immagine che siamo: ritratto e soggettivita1 nell'estteica contemporanea. Roma: Carocci, 2014. p. 13-26.

BOEHM, Gottfried. Aquilo que se mostra: sobre a diferença icônica. In: ALLOA, Emmanuel (org.). Pensar a imagem. São Paulo: Autêntica, 2015. p. 23-38.

BREA, José Luis (org.). Estudios visuales: la epistemologia de la visualidad en la era de la globalización. Madrid: Akal, 2005.

BREDEKAMP, Horst. A neglected tradition? Art history as Bildwissenschaft. Critical Inquiry, Chicago, v. 29, n. 3, p. 418-428, 2003.

BREDEKAMP, Horst. Immagine che ci Guardano: teoria dell'atto iconico. Milano: Cortina, 2015.

BREDEKAMP, Horst. Nostalgia dell'antico e fascino della machina: il futuro della storia dell'arte. Milano: Il Saggiatore, 2016.

BRENNAN, Teresa. "The contexts of vision" from a specific standpoint. In: BRENNAN, Teresa; JAY, Martin (eds.). Vision in context: historical and contemporary perspectives on sight. London: Routledge, 1996. p. 217-230.

BRENNAN, Teresa; JAY, Martin (eds.). Vision in context: historical and contemporary perspectives on sight. London: Routledge, 1996. 
BRYSON, Norman. Word and image: French paiting of the Ancien Regime. Cambridge: Paperback, 1983.

BRYSON, Norman. Vision and painting: the logic of the gaze. New Haven: Yale University Press, 1986.

BRYSON, Norman; HOLLY, Michael Ann; MOXEY, Keith (eds.). Visual theory: painting and interpretation. Cambridge: Polity Press: Blackwell, 1991.

CAMMARATA, Valeria. W. J. T. Mitchell in Italia. In: MITCHELL, William John T. Pictorial turn: saggi di cultura visual. Milano: Raffaello Cortina, 2017. p. 217-236.

CAPRETTINI, Gian Paolo. Imagem. In: ENCICLOPEDIA Einaudi. Porto: Imprensa Nacional/ Casa da Moeda, 1994. p. 177-199.

CARVALHO, Vânia. Gênero e artefato: o sistema doméstico na perspectiva da cultura material. São Paulo: Edusp, 2008.

CARVALHO, Vânia; LIMA, Solange. Fotografia e cidade: da razão urbana à lógica do consumo. Campinas: Mercado de Letras, 1997.

COMETA, Michele. Parole che dipingono: letteratura e cultura visuale tra Settecento e Novecento. Roma: Meltemi, 2004.

COMETA, Michele. La Scrittura delle immagine: letteratura e cultura visuale. Milano: Raffaelo Cortina, 2012.

COMETA, Michele. Prefazione all'edizione italiana. In: MITCHELL, William John Thomas. Pictorial turn: saggi di cultura visual. Milano: Raffaello Cortina, 2017. p. 9-40.

CONDURU, Roberto. Ilbas da razão: arquitetura racionalista do Rio de Janeiro no século XX. 2000. Tese (Doutorado em História) - Universidade Federal Fluminense, Niterói, 2000.

CONTE; Pietro. "Una sorta di intelligenza iconica": immagine e conoscenza intuitiva. Lebenswelt, Milano, n. 2, p. 191-201, 2012.

COSTA, Eduardo; SCHIAVINATTO, Iara Lis (orgs.). Cultura visual e história. São Paulo: Alameda, 2016. 
CRARY, Jonathan. Técnicas do observador. São Paulo: Contraponto, 2012.

CURTIS, Neal (org.). The pictorial turn. London: Routledge, 2010.

DANTO, Arthur. Depiction and description. Philosophy and phenomenological research, Providence, v. 43, n. 1, p. 1-19, 1982.

DIAS, Eliane. Paisagem e academia: Félix-Émile Taunay e o Brasil (1824-1851). Campinas: Editora Unicamp, 2009.

DIDI-HUBERMAN, Georges. O que vemos, o que nos olha. São Paulo: Editora 34, 1998.

DIDI-HUBERMAN, Georges. Beato Angelico: figure del dissimile. Milano: Abscondita, 2014.

DIDI-HUBERMAN, Georges. Devant l'image: question posée aux funs d'une histoire de l'art. Paris: Minuit, 1990.

DIDI-HUBERMAN, Georges. Diante do tempo: história da arte e a anacronia nas imagens. Belo Horizonte: Editora UFMG, 2016.

DIDI-HUBERMAN, Georges. L'image survivance: historie de l'art et temps des fantômes selon Aby Warburg. Paris: Minuit, 2002.

DIDI-HUBERMAN, Georges. Sobrevivência dos vaga-lumes. Belo Horizonte: Editora UFMG, 2011.

DIKOVITSKAYA, Margaret. Visual culture: the study of the visual after the cultural turn. London: MIT Press, 2005.

DOTTORI, Riccardo, KUNKLER, Horst. (orgs.). Estetica ed Ermeneutica. Napoli: Pironti, 1981, p. 121-134.

ELKINS, James. Visual studies: a skeptical introduction. London: Routledge, 2003.

ELKINS, James. La storia dell'arte e le immagini che arte non sono. In: PINOTTI, Andrea; SOMAINI, Antonio (orgs.). Teorie dell'Immagine: il dibattio contemporâneo. Milano: Rafaello Cortina, 2009. p. 155-208.

ESPOSITO, Roberto. Pensiero vivente: origine e attualità della filosofia italiana. Torino: Einaudi, 2010. 
FABRIS, Annateresa (org.). Fotografia: usos e funções no século XIX. São Paulo: Edusp, 1998.

FARAGO, Claire. A cultura visual é aplicada com utilidade a objetos pré-modernos? Por que isso importa? In: COSTA, Eduardo; SCHIAVINATTO, Iara Lis (orgs.). Cultura visual e história. São Paulo: Alameda, 2016. p. 31-52.

FERNANDES, Cássio. Jacob Burkhardt e Aby Warburg: da arte à civilização do Renascimento. Locus, Juiz de Fora, v. 12, n. 1, 127-143, p. 2006.

FIEDLER, Konrad. Scritti sull'arte figurativa. Palermo: Aesthetica, 2006.

FLORES, Maria Bernardete Ramos (org.). Dossiê O tempo da imagem. ArtCultura, Uberlândia, v. 12 , n. $21,2010$.

FLORES, Maria Bernardete Ramos (org.). História e arte: movimentos artísticos e correntes intelectuais. Campinas: Mercado de Letras, 2011.

FLORES, Maria Bernardete Ramos (org.). História e arte: utopia, utopias. Campinas: Mercado de Letras, 2013.

FOUCAULT, Michel. As palavras e as coisas. São Paulo: Martins Fontes, 2005.

FOUCAULT, Michel. A arqueologia do saber. Rio de Janeiro: Forense Universitária, 2012.

FOSTER, Hal (ed.). Vision and visuality. Seattle: Bay Press, 1988.

FREEDBERG, David. The power of images. Chicago: University of Chicago Press, 1989.

FREEDBERG, David; GALLESE, Vittorio. Movimento, emozione ed empatia nell'esperienza estetica. In: PINOTTI, Andrea; SOMAINI, Antonio (orgs.). Teorie dell'immagine: il dibattio contemporâneo. Milano: Rafaello Cortina, 2009. p. 331-352.

GADAMER, Hans Georg. Parola e immagine. In: GADAMER, Hans Georg. Linguaggio. Roma: Laterza, 2005. p. 169-198.

GAY, Peter. Modernismo: o fascínio da heresia. São Paulo: Companhia das Letras, 2009. 
GEIMER, Peter. Photography as a "space of experience": on the retrospective legibility of historic photographs. Getty Research Journal, Chicago, v. 7, p. 97-108, 2015.

GELL, Alfred. Art and agency: an anthropological theory. Oxford: Oxford University Press, 1998.

GINZBURG, Carlo. De Warburg a Gombrich. In: GINZBURG, Carlo. Mitos, emblemas, sinais: morfologia história. São Paulo: Companhia das Letras, 2009.

GINZBURG, Carlo. Representação: a palavra, a idéia, a coisa. In: GINZBURG, Carlo. Olhos de madeira: nove reflexões sobre a distância. São Paulo: Companhia das Letras, 2001. p. 85-103.

GINZBURG, Carlo. Paura, reverenza, terrore. Milano: Adelphi, 2015.

GOMBRICH, Ernest. Arte e ilusão: um estudo da psicologia da representação. São Paulo: Martins Fontes, 2007.

GRIFFERO, Tonino. La (irresistibile?) carriera delle imagine. In: BOEHM, Gottfried. La svolta iconica. Roma: Meltemi, 2009. p. 297-298.

GRUZINSKI, Serge. A guerra das imagens: de Cristovão Colombo a Blade Runner (1492-2019). São Paulo: Companhia das Letras, 2006.

GUIMARÃES, Manoel Luiz Salgado. Vendo o passado: representação e escrita da história. Anais do Museu Paulista, São Paulo, v. 15, n. 2, p. 11-30, 2007.

HENTSCHEL, Klaus. Visual culture in science and technology: a comparative history. Oxford: Oxford University Press, 2014.

HUCHET, Stéphane (org.). Fragmentos de uma teoria da arte. São Paulo: Edusp, 2012.

IMDAHL, Max. Iconica: l'intuizione delle immagini. Aisthesis, Firenze, ano 5, n. 2, p. 11-32, 2012.

JAY, Martin. Downcast eyes: the denigration of vision in Twentieth-Century French thought. Los Angeles: University of California Press, 1993.

JAY, Martin. Visual culture and its vicissitudes. October, Cambridge, n. 77, p. 42-44, 1996a. 
JAY, Martin. Vision in context: reflections and refractions. In: BRENNAN, Teresa; JAY, Martin (eds.). Vision in context: historical and contemporary perspectives on sight. London: Routledge, 1996b. p. 1-12.

JAY, Martin. Relativismo cultural e a virada visual. Aletria, São Paulo, v. 10-11, p. 14-29, 2003-2004.

JAY, Martin. Scopic regimes of modernity. In: FOSTER, Hal (ed.). Vision and visuality. Seattle: Bay Press, 1988. p. 3-23.

JENKS, Chris (ed.). Visual culture. London: Routledge, 1995.

KEMP, Martin. The science of art. New Haven: Yale University Press, 1990.

KERN, Maria Lúcia Bastos; KAMINSKI, Rosane. As imagens no tempo e os tempos da imagem. História, Curitiba, v. 61, n. 2, p. 6-14, 2014.

KNAUSS, Paulo. Imaginária urbana e poder simbólico: escultura pública no Rio de Janeiro e Niterói. 1998. Tese (Doutorado em História) - Universidade Federal Fluminense, Niterói, 1998.

KNAUSS, Paulo. O desafio de fazer história com imagens: arte e cultura visual. ArtCultura, Uberlândia, v. 8, p. 97-119, 2006.

KNAUSS, Paulo. Aproximações disciplinares: arte, história, imagem. Anos 90, Porto Alegre, v. 15 , n. 28, p. $151-168,2008$.

KOSSOY, Boris. Fotografia e história. São Paulo: Ateliê, 2001.

KRAUSS, Rosalind. Welcome to the cultural revolution. October, Cambridge, n. 77, p. 83-96, 1996.

LACAN, Jacques. O Seminário - livro 11: os quatro conceitos fundamentais da psicanálise. Rio de Janeiro: Jorge Zahar, 1985.

LARA, Silvia. Fragmentos setecentistas. São Paulo: Companhia das Letras, 2005.

LATOUR, Bruno. Che cos'è iconoclash. In: PINOTTI, Andrea; SOMAINI, Antonio (orgs.). Teorie dell'immagine: il dibattio contemporâneo. Milano: Rafaello Cortina, 2009. p. 287-330.

LEHMKUHL, Luciene. A história por entre artes e imagens. ArtCultura, Uberlândia, v. 8, n. 12, p. 1-2, 2006. 
LIMA, Valéria. J. B. Debret: historiador e pintor. Campinas: Editora da Unicamp, 2007.

LISSOVSKY, Maurício. A vida póstuma de Aby Warburg: por que seu pensamento seduz os pesquisadores contemporâneos da imagem. Boletim do Museu Paraense Emílio Goeldi, Belém, v. 9, n. 2, p. 305-322, 2014.

LUCAS, Meize Regina de Lucena. Caravana Farkas: itinerários do documentário brasileiro. 2005. Tese (Doutorado em História) -Universidade Federal do Rio de Janeiro, 2005.

MAcGAFFEY, Wyatt. Kongo political culture: the conceptual challenge of the particular. Indianapolis: Indiana University Press, 2000.

MALTA, Marize. O olhar decorativo: ambientes domésticos em fins do século XIX no Rio de Janeiro. Rio de Janeiro: Mauad: Faperj, 2011.

MAUAD, Ana Maria. Imagem e auto-imagem do império. In: ALENCASTRO, Luiz Felipe (org.). História da vida privada no Brasil Império: a corte e a modernidade nacional. São Paulo: Companhia das Letras, 1997. p. 181-232.

MAUAD, Ana Maria. Poses e flagrantes. Rio de Janeiro: Eduff, 2008.

MAUAD, Ana Maria. Como nascem as imagens? Um estudo de história visual. História, Curitiba, n. 61, p. 105-132, 2014.

MAUAD, Ana Maria; LOPES, Marcos Felipe de Brum (orgs.). Imagem, história e ciência. Boletim do Museu Paraense Emílio Goeldi, Belém, v. 9, n. 2, p. 283-286, 2014.

MAUAD, Ana Maria; MONTEIRO, Charles. Fotografia, cultura visual e história: perspectivas teóricas-metodológicas. Estudos Ibero-americanos, Porto Alegre, v. 44, n. 1, p. 3-5, 2018.

MELANDRI, Enzo. Per una filosofia della metafora. In: BLUMENBERG, Hans. Paradigmi per una metaforologia. Milano: Raffaelo Cortina, 2018. p. 157-164.

MENEGUELlo, Cristina. Da ruína ao edifício. São Paulo: Annablume, 2008.

MENESES, Ulpiano. Memória e cultura material: documentos pessoais no espaço público. Estudos Históricos, Rio de Janeiro, v. 11, n. 21, p. 89-104, 1998. 
MENESES, Ulpiano. Fontes visuais, cultura visual, história visual. Revista brasileira de história, São Paulo, v. 23, n. 45, p. 11-36, 2004.

MENESES, Ulpiano. Rumo a uma história visual. In: MARTINS, José de Souza; ECKERT, Cornélia; NOVAES, Sylvia Caiuby (orgs.). O imaginário e o poético nas ciências sociais. Florianópolis: Edusc, 2005. p. 33-56.

MENESES, Ulpiano. História e imagem: iconografia/iconologia e além. In: CARDOSO, Ciro; VAINFAS, Ronaldo. Novos domínios da bistória. Rio de Janeiro: Civilização Brasileira, 2012. p. 243-261.

MERLEAU-PONTY, Maurice. A dúvida de Cézanne. In: O olbo e o espírito. Trad. Paulo Neves e Maria E. Galvão Gomes Pereira. São Paulo: Cosac \& Naify, 2004. p. 121-160.

MIRZOEFF, Nicholas (org.). The visual culture reader. London e New York: Routledge, 1998.

MIRZOEFF, Nicholas. An introduction to visual culture. London: Routledge, 1999.

MIRZOEFF, Nicholas. An introduction to visual culture. 2 ed. London: Routledge, 2009.

MIRZOEFF, Nicholas. Come vedere il mondo. Cremona: Johan e Levi, 2018.

MITCHELL, William John Thomas (org.). The language of images. Chicago: University of Chicago Press, 1980.

MITCHELL, William John Thomas. Blake's composite art: a study of the illuminated poetry. Princeton: Princeton University Press, 1983.

MITCHELL, William John Thomas. What is an image? New Literary History, Baltimore, v. 15, n. 3, p. 503-537, 1984.

MITCHELL, William John Thomas. Iconology. Chicago: University of Chicago Press, 1986 .

MITCHELL, William John Thomas. The idea of image. Iconology. Chicago: University of Chicago Press, 1986b. p. 5-6.

MITCHELL, William John Thomas. Picture theory: essays on verbal and visual representation. Chicago: The University of Chicago, 1994. 
MITCHELL, William John Thomas. What do pictures really want? October, Cambridge, n. 77, p. 71-82, 1996.

MITCHELL, William John Thomas. Showing seeing. Journal of Visual Culture, Thousand Oaks, n. 1, v. 2, p. 165-181, 2002.

MITCHELL, William John Thomas. What do pictures want? The lives and loves of images. Chicago: University of Chicago Press, 2005.

MITCHELL, William John Thomas. Como caçar (e ser caçado) por imagens. [Entrevista cedida a] Daniel B. Portugal e Rose de Melo Rocha. E-compós, Brasília, DF, v. 12, n. 1, p. 1-17, 2009 a.

MITCHELL, William John Thomas. Cosa vogliono le immagini. In: PINOTTI, Andrea; SOMAINI, Antonio (orgs.). Teorie dell'Immagine: il dibattito contemporaneo. Milano: Raffaello Cortina, 2009b. p. 99-136.

MITCHELL, William John Thomas. Clonning terror: the war of images, 9/11 to the present. Chicago: University Chicago Press, 2011.

MITCHELL, William John Thomas. Pictorial turn: una risposta. Lebenswelt, Milano, n. 2, p. 130-143, 2012.

MITCHELL, William John Thomas. Image science: iconology, visual culture and media aesthetics. Chicago: University of Chicago Press, 2015a.

MITCHELL, William John Thomas. O que as imagens realmente querem? In: ALLOA, Emanuel (org.). Pensar a imagem. São Paulo: Alameda, 2015b. p. 165-190.

MITCHELL, William John Thomas. Four fundamental concepts of Image Science. Image science: iconology, visual culture and media aesthetics. Chicago: University of Chicago Press, 2015c.

MONDZAIN, Marie-José. Imagem, icone, economia: as fontes bizantinas do imaginário contemporâneo. São Paulo: Contraponto, 2013.

MONTE, Maria Giuseppina di; MONTE, Michele di (orgs.). Introduzione. BOEHM, Gottfried. La svolta iconica Roma: Meltemi, 2009. p. 7-36.

MONTEIRO, Charles. La construcción de una visualidad urbana moderna en las revistas ilustradas brasileñas de los años 1920. In: MINGUEZ, Victor; BORGES, Maria Eliza Linhares 
(orgs.). La fabricación visual del Mundo Atlántico (1808-1940). Castelló de la Plana: Publicacions de la Universitat Jaume I, 2010. p. 245-266.

MONTEIRO, Charles (org.). Fotografia, história e cultura visual: pesquisas recentes. Porto Alegre: EdiPUCRS, 2012.

MONTEIRO, Charles. Pensando sobre história, imagem e cultura visual. Patrimônio e Memória, Assis, v. 9, n. 2, p. 3-16, 2013.

MOXEY, Keith. Visual studies and the iconic turn. Journal of Visual Culture, Thousand Oaks, n. 7, p. 131-134, 2008.

MOXEY, Keith. Contemporaneity's heterochronicity. In: MOXEY, Keith. Visual time: the image in history. Durham: Duke University Press, 2013a. p. 37-51.

MOXEY, Keith. A "virtual cosmopolis": Partha Mitter in conversation with Keith Moxey. The Art Bulletin, New York, v. 95, n. 3, p. 381-392, 2013 b.

MULVEY, Laura. Prazer visual e cinema narrativo. In: XAVIER, Ismail (org.). A experiência de cinema. Rio de Janeiro: Graal, 1983. p. 437-453.

MULVEY, Laura. Reflexões sobre 'Prazer visual e cinema narrativo' insporadas no Duelo ao Sol, de king Vidor (1946). In: RAMOS, Fernão (org.). Teoria contemporânea do cinema. Vol. 1. São Paulo: Senac, 2005. p. 381-392.

PANOFSKY, Erwin. Idea: a evolução do conceito de belo. São Paulo: Martins Fontes, 2013.

PANOFSKY, Erwin. Perspective as symbolic form. New York: Zone Books, 1991.

PEREIRA, Ana Carolina Barbosa. Precisamos falar sobre o lugar epistêmico na teoria da história. Tempo E Argumento, Florianópolis, v. 10, n. 24, p. 88-114, 2018.

PINOTTI, Andrea; LUCIGNANI, Giovanni (orgs.). Immagine della mente. Milano: Raffaello Cortina, 2009.

PINOTTI, Andrea; SCRIVANO, Fabrizio. Appendice biobliografica. In: FIEDLER, Konrad. Scritti sull'arte figurativa. Palermo: Aesthetica, 2006. p. 217-243. 
PINOTTI, Andrea; SOMAINI, Antonio (orgs.). Teorie dell'immagine: il dibattito contemporaneo. Milano: Raffaello Cortina, 2009.

PINOTTI, Andrea; SOMAINI, Antonio. Introduzione. In: PINOTTI, Andrea; SOMAINI, Antonio (orgs.). Teorie dell'immagine: il dibattito contemporaneo. Milano: Raffaello Cortina, 2009. p. 9-38.

PINOTTI, Andrea; SOMAINI, Antonio. Cultura visuale: imagine, sguardo, media, dispositivi. Milano: Einaudi, 2016.

PINOTTI, Andrea; TEDESCO, Salvatore (orgs.): Estetica e scienze della vita. Milano: Raffaello Cortina, 2013.

POLANYI, Michael. What is a painting? The American scholar, Boston, v. 39, n 4, p. 655-669, 1970.

RECHT, Roland. A escritura da história da arte diante dos modernos: observações a partir de Riegl, Wölfflin, Warburg e Panofsky. In: HUCHET, Stéphane (org.). Fragmentos de uma teoria da arte. São Paulo: Edusp, 2012. p. 33-60.

REDE, Marcelo. História e cultura material. In: CARDOSO, Ciro; VAINFAS, Ronaldo. Novos domínios da história. Rio de Janeiro: Civilização Brasileira, 2012. p. 133-150.

ROSSI, Paolo. A chave universal. Bauru, SP: EDUSC, 2004.

RUBINO, Silvana Barbosa. Rotas da modernidade: trajetória, campo e história na atuação de Lina Bo Bardi, 1947-1968. 2002. Tese (Doutorado em Antropologia) -Universidade Estadual de Campinas, Campinas, 2002.

RUSCHI, Ricardo (org.). Estetica tedesca oggi. Milano: Unicopli, 1986.

SANDBERG, Mark. Effigy and narrative: looking into the 19th Folk Museum. In: CHARNEY, Leo; SCHWARTZ, Vanessa (orgs.). Cinema and the invention of modern life. Los Angeles: University of California Press, 1995. p 320- 360.

SANTIAGO JÚNIOR, Francisco das Chagas F. Imagens do candomblé e da umbanda: etnicidade e religião no cinema brasileiro nos anos 1970. 2009. Tese (Doutorado em História) Universidade Federal Fluminense, Niterói, 2009.

SCHAPIRO, Meyer. On some problems in the semiotics of visual art. Simiolus, Amsterdan, v. 6, n. 1, p. 9-19, 1973. 
SCHIAVINATTO, Iara Lis. Pátria coroada: o Brasil como corpo político autônomo, 1780-1831. São Paulo: Editora Unesp, 1999.

SCHMITT, Jean-Claude. O corpo das imagens: ensaios sobre a cultura visual na Idade Média. São Carlos: Edusc, 2007.

SCHØLLHAMMER, Karl Erik. Regimes representativos da modernidade. Alceu, Rio de Janeiro, v. 1, n. 2, p. 28-41, 2001.

SCHVARZMAN, Sheila. Humberto Mauro e as imagens do Brasil. São Paulo: Hucitec, 2004.

SCHWARCZ, Lilian Moritz. O sol do Brasil: Nicolas-Antoine Taunay e as desventuras dos artistas franceses na corte de D. João. São Paulo: Companhia das Letras, 2008.

SCHWARCZ, Lilian Moritz. As barbas do Imperador: D Pedro II, um monarca nos trópicos. São Paulo: Companhia das Letras, 1998.

SEVERI, Carlo. L'oggetto-persona: rito, memoria, immagine. Torino: Einaudi, 2018.

SETTIS, Salvatore. Il Futuro del classico. Milano: Einaudi, 2004.

SLENES, Robert. As provações de um Abraão africano: a nascente nação brasileira na viagem alegórica de Johann Moritz Rugendas. Revista de história da arte e arqueologia, Campinas, $\mathrm{n}$. 2, p. 271-296, 1995.

SOUZA, Fábio Feltrin et al. (orgs.). Cultura visual e ensino. PerCursos, Florianópolis, v. 17, n. 33, 2016. ISSN: 1984-7246.

VARGIU, Luca. Boehm, Mitchell e una storia ancora da scrivere. Lebenswelt, Milano, n. 2, p. 160-171, 2012.

VERNANT, Jean-Pierre. Entre mito e política. São Paulo: Edusp, 2001.

WEIGEL, Sigrid. The flash of knowledge and the temporality of images. Critical Inquiry, Chicago, v. 41, n. 2, p. 344-366, 2015.

WUNENBURGER, Jean-Jacques. Filosofia delle Immagini. Torino: Einaudi, 1999.

YATES, Frances. A arte da memória. Campinas: Editora Unicamp, 2007. 
APES**T: the Carters. [S. 1.: s. n.]. 2018. 1 vídeo (6’05 min). Publicado pelo canal Beyoncé. Disponível em: <https://bit.ly/2MvEyAo>. Acesso em: 14 jan. 2019.

A PRISÃO de Lula em imagens: choro e raiva de um lado, fogos e panelas de outro. El País, [s. 1.], 8 abr. 2018. Disponível em: <https://bit.ly/2FrNK8M>. Acesso em: 14 jan. 2019.

GONÇALVES, Juliana. “Queimem a bruxa!” Visita de Judith Butler provoca manifestações nas ruas de São Paulo. The Intercept Brasil, [s. 1.], 7 nov. 2017. Disponível em: <https://bit. ly/2zqfo2f>. Acesso em: 14 jan. 2019.

GOVERNO faz denúncia ao MP de adesivo como ofensa a Dilma. Portal Terra, [s. 1.], 2 jul. 2015. Disponível em: <https://bit.ly/2qyLqmL>. Acesso em: 14 jan. 2019.

PEDIDO de retirada das estátuas do São Francisco gera polêmica. Portal G1, Rio de Janeiro, 13 nov. 2015. Disponível em: <https://glo.bo/2SYP3il>. Acesso em: 14 jan. 2019.

PRESSE, Francisco. Destruição de Palmira seria enorme perda para humanidade, diz UNESCO. Portal G1, Rio de Janeiro, 21 maio 2015. Disponível em: <https://glo.bo/2RUeW61>. Acesso em: 14 jan. 2019.

Artigo apresentado em 08/08/2018. Aprovado em 17/12/2018.

\section{(cc) BY}

